\title{
Purification and In Vitro Evaluation of an Anti-HER2 Affibody-Monomethyl Auristatin E Conjugate in HER2-Positive Cancer Cells
}

\author{
Isabella Damiani ${ }^{1}$, Silvia Castiglioni ${ }^{1}$, Alicja Sochaj-Gregorczyk ${ }^{2}$, Fabrizia Bonacina ${ }^{1}\left(\mathbb{D}\right.$, Irma Colombo ${ }^{1}{ }^{1}$, \\ Valentina Rusconi ${ }^{1}$, Jacek Otlewski ${ }^{3}{ }^{(0)}$, Alberto Corsini ${ }^{1,4}{ }^{(\mathbb{D}}$ and Stefano Bellosta ${ }^{1, *(D)}$
}

1 Department of Pharmacological and Biomolecular Sciences, Università degli Studi di Milano, 20133 Milan, Italy; isabella.damiani@unimi.it (I.D.); silvia.castiglioni@unimi.it (S.C.); fabrizia.bonacina@unimi.it (F.B.); irma.colombo@unimi.it (I.C.); valentina.rusconi2@studenti.unimi.it (V.R.); alberto.corsini@unimi.it (A.C.)

2 Microbiology Department, Faculty of Biochemistry, Biophysics and Biotechnology, Jagiellonian University, Gronostajowa 7, 30387 Krakow, Poland; alicja.sochaj-gregorczyk@uj.edu.pl

3 Department of Protein Engineering, Faculty of Biotechnology, University of Wroclaw, 50137 Wroclaw, Poland; jacek.otlewski@uwr.edu.pl

4 IRCCS MultiMedica, Sesto San Giovanni, 20099 Milan, Italy

* Correspondence: stefano.bellosta@unimi.it; Tel.: +39-0250318392

Citation: Damiani, I.; Castiglioni, S.; Sochaj-Gregorczyk, A.; Bonacina, F; Colombo, I.; Rusconi, V.; Otlewski, J.; Corsini, A.; Bellosta, S. Purification and In Vitro Evaluation of an Anti-HER2 Affibody-Monomethyl Auristatin E Conjugate in HER2-Positive Cancer Cells. Biology 2021, 10, 758. https://doi.org/ 10.3390/biology10080758

Received: 1 July 2021

Accepted: 4 August 2021

Published: 7 August 2021

Publisher's Note: MDPI stays neutral with regard to jurisdictional claims in published maps and institutional affiliations.

Copyright: () 2021 by the authors. Licensee MDPI, Basel, Switzerland. This article is an open access article distributed under the terms and conditions of the Creative Commons Attribution (CC BY) license (https:// creativecommons.org/licenses/by/ $4.0 /)$.
Simple Summary: Antibody-drug conjugates (ADCs) represent an innovative class of anticancer agents specifically aimed at targeting cancer cells, reducing damage to healthy tissues but showing some weaknesses. A promising approach for the development of high-affinity tumor targeting ADCs is the use of engineered protein drugs, such as affibody molecules. Our aim was to develop a more efficient purification method for the cytotoxic conjugate $Z_{\text {HER2:2891 }}$ DCS-MMAE that targets human epidermal growth factor receptor 2 (HER2)-positive breast cancer cells. The conjugate is based on $\mathrm{Z}_{\mathrm{HER} \text { :2891 }}$ affibody and a drug conjugation sequence (DCS), which allowed for sitespecific conjugation of the cytotoxic auristatin E molecule (MMAE) to the affibody. We tested the in vitro efficacy of $Z_{\text {HER2:2891 }}$ DCS-MMAE on several parameters, such as cell viability, proliferation, migration, and apoptosis. Our results confirmed that the cytotoxic conjugate efficiently interacts with high affinity with HER2 positive cancer cells, allowing the selective and specific delivery of the cytotoxic payload.

Abstract: A promising approach for the development of high-affinity tumor targeting ADCs is the use of engineered protein drugs, such as affibody molecules, which represent a valuable alternative to monoclonal antibodies (mAbs) in cancer-targeted therapy. We developed a method for a more efficient purification of the $\mathrm{Z}_{\mathrm{HER} 2: 2891}$ DCS affibody conjugated with the cytotoxic antimitotic agent auristatin E (MMAE), and its efficacy was tested in vitro on cell viability, proliferation, migration, and apoptosis. The effects of $Z_{\text {HER2:2891 }}$ DCS-MMAE were compared with the clinically approved monoclonal antibody trastuzumab (Herceptin ${ }^{\circledR}$ ). To demonstrate that $Z_{\text {HER2:2891 }}$ DCS-MMAE can selectively target HER2 overexpressing tumor cells, we used three different cell lines: the human adenocarcinoma cell lines SK-BR-3 and ZR-75-1, both overexpressing HER2, and the triple-negative breast cancer cell line MDA-MB-231. MTT assay showed that $Z_{\text {HER2:2891 }}$ DCS-MMAE induces a significant time-dependent toxic effect in SK-BR-3 cells. A 30\% reduction of cell viability was already found after $10 \mathrm{~min}$ exposure at a concentration of $7 \mathrm{nM}$ ( $\mathrm{IC}_{50}$ of $\left.80.2 \mathrm{nM}\right)$. On the contrary, MDA-MB231 cells, which express basal levels of HER2, were not affected by the conjugate. The cytotoxic effect of the $Z_{\text {HER2:2891 }}$ DCS-MMAE was confirmed by measuring apoptosis by flow cytometry. In SK-BR-3 cells, increasing concentrations of conjugated affibody induced cell death starting from $10 \mathrm{~min}$ of treatment, with the strongest effect observed after $48 \mathrm{~h}$. Overall, these results demonstrate that the ADC, formed by the anti-HER2 affibody conjugated to monomethyl auristatin E, efficiently interacts with high affinity with HER2 positive cancer cells in vitro, allowing the selective and specific delivery of the cytotoxic payload. 
Keywords: affibody; breast cancer; HER2 overexpression; target therapy

\section{Introduction}

The human epidermal growth factor receptor 2 (HER2) is a tyrosine kinase receptor that belongs to the family of the epidermal growth factor receptors (EGFRs).

Amplification of HER2 gene is observed in 20-30\% of human cancers, especially breast and ovarian cancers [1], and in about $30 \%$ of feline mammary carcinomas (FMCs) [2], while its overexpression is correlated with poor prognosis and worse clinical outcomes [3]. The overexpression of HER2 in tumor cells leads to the activation of various signaling pathways involved in cellular proliferation, migration, and apoptosis suppression [4]. Thus, HER2 represents an important pharmacological target for HER2-positive breast cancer therapy. The most used drug targeting HER2 is trastuzumab (Herceptin ${ }^{\circledR}$ ). This is a humanized IgG1 monoclonal antibody $(\mathrm{mAb})$ that binds to the extracellular domain of the human HER2 protein and is currently used in patients with metastatic breast or gastric cancer characterized by HER2 overexpression [5]. Trastuzumab seems to exert its therapeutic effect through different mechanisms, including the activation of antibody-dependent cellular cytotoxicity [6], the inhibition of the MAPK and PI3K/AKT pathways [7], leading to cell cycle arrest, and by blocking the shedding of the HER2 extracellular domain [8].

Trastuzumab, when combined with chemotherapy, improves overall survival in patients with HER2-positive breast cancer [9]. However, the clinical efficacy of trastuzumab is limited, due to the development of resistance to the drug in a significant number of women with HER2 overexpressing tumors [10].

Target therapy using specific antibodies conjugated with a cytotoxic drug represents an innovative strategy in cancer treatment and a valid alternative to naked antibodytargeted therapy [11]. Antibody-drug conjugates (ADCs) combine the highly specific targeting of $\mathrm{mAbs}$ with the potent cytotoxic activity of small molecule agents. The Food and Drug Administration (FDA) approved two ADCs, brentuximab vedotin (Adcetris ${ }^{\circledR}$ ) and trastuzumab emtansine $\left(\operatorname{Kadcyla}^{\circledR}\right)$, for the treatment of patients with Hodgkin lymphoma and HER2 metastatic breast cancer, respectively [12]. Brentuximab vedotin consists of an anti-CD30 antibody linked to the potent antimitotic drug monomethyl auristatin E (MMAE) [13], whereas trastuzumab emtansine combines trastuzumab with another antimitotic cytotoxic agent, derivative of maytansine (DM1), via a chemical linker [14] Interestingly, a recent paper described the use of anti-HER2 mAbs and ADCs as a new targeted therapy for feline FMC [15]. Although several ADCs are currently used in clinics, they show some limitations due to their large size (mAbs are $150 \mathrm{kDa}$ and over), which reduces their ability to penetrate solid tumors, and associated high production cost [16].

To overcome these limitations, a new class of affinity ligands based on non-antibody scaffolds has become an attractive alternative to $\mathrm{mAbs}$, due to their smaller size of $\sim 6.5 \mathrm{kDa}$ compared to whole antibodies or antibody fragments $(\sim 20-150 \mathrm{kDa})$, a rapid blood clearance that allows for faster penetration and distribution into tissues, and cost-efficient production in prokaryotic hosts (Escherichia coli), in contrast to mAbs that are mainly produced in mammalian cells [17].

These small molecules called affibodies are derived from mutagenesis at specific amino acid residues of the B domain of staphylococcal protein A to increase their chemical stability. The resulting engineered variant is called the $Z$ domain [18]. This $Z$ domain consists of 58 amino acids, and 13 of these surface amino acid residues were randomized to generate affibody libraries, followed by phage display selection against different target proteins, including HER2, EGFR, and amyloid- $\beta$ peptide $[19,20]$.

In the present study, we developed a rapid and simple method for $Z_{\mathrm{HER} 2: 2891} \mathrm{DCS}$ purification that, in contrast to the previously described procedure [21], does not require protein tagging. According to previous studies, mAbs conjugated with MMAE show selective antitumor activity in patients with solid tumors [22]. For this reason, we decided 
to conjugate our affibody to auristatin E, a synthetic analogue of the natural product dolastatin 10 that acts by inhibiting cell division and blocking the polymerization of tubulin $[23,24]$. MMAE is extremely cytotoxic and is not tumor-specific, for these reasons it cannot be used as a drug itself. However, it is clinically used as payload in ADCs such as brentuximab vedotin and polatuzumab vedotin-piiq [13,25]. Abdollahpour-Alitappeh et al. and Sochaj-Gregorczyk et al. demonstrated by MTT and Alamar Blue assay that free MMAE is cytotoxic in several breast and kidney cancer cell lines tested, with an $\mathrm{IC}_{50}$ value in the nanomolar range [21,26].

In a previous study, Sochaj-Gregorczyk et al. used an affinity chromatography approach for the purification of the anti-HER2 affibody $Z_{\text {HER2:2891 }} D C S$, since $Z_{\text {HER2:2891 }}$ DCS was tagged with GST ( $Z_{\text {HER2:2891 }}$ DCS-GST) [21]. However, this purification method gave only 1-5 mg of protein from 1-litre culture. Therefore, we set up another, more efficient and faster method to purify $Z_{\mathrm{HER} 2: 2891} \mathrm{DCS}$ and then characterized its in vitro binding to HER2 and how it might affect cancer cells.

\section{Materials and Methods}

\subsection{Generation of the $p D E S T 15-G S T$ Removed- $Z_{H E R 2: 2891-D C S}$}

To remove the sequence that encodes for the GST tag from the pDEST15- $Z_{\text {HER22891 DCS }}$ construct, inverse PCR with 5'-phosphorylated primers (Table 1) was performed.

Table 1. List of 5'-phosphorylated primers.

\begin{tabular}{cc}
\hline Forward Primer & Reverse Primer \\
\hline $5^{\prime}$ GCCGAAGCCAAATATGCA $3^{\prime}$ & $5^{\prime}$ CATATGTATATCTCCTTC $3^{\prime}$ \\
$3^{\prime}$ CGGCTTCGGTTTATACGT 5 & $3^{\prime}$ GTATACATATAGAGGAAG 5 ${ }^{\prime}$ \\
\hline
\end{tabular}

Subsequently, the PCR product was subjected to ligation using T4 DNA ligase (Thermo Fisher Scientific). The resulting construct pDEST-GST removed-Z $\mathrm{Z}_{\mathrm{HER} 2: 2891} \mathrm{DCS}$ was verified by sequencing (LGC Genomics), which confirmed that the sequence encoding GST had been removed.

\subsection{Affibody Expression}

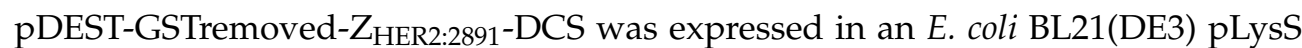
strain. E. coli were grown on Luria Bertani (LB) medium supplemented with $100 \mu \mathrm{g} / \mathrm{mL}$ ampicillin and $100 \mu \mathrm{g} / \mathrm{mL}$ of chloramphenicol. The expression of $Z_{\text {HER2:2891 }}$ DCS affibody was induced by the addition of $0.5 \mathrm{mM}$ Isopropyl $\beta$-D-1-thiogalactopyranoside. Cells were incubated at $37^{\circ} \mathrm{C}$ for $4 \mathrm{~h}$ and then harvested.

\subsection{Affibody Purification}

Bacterial pellets were resuspended in an ion exchange buffer (50 mM HEPES buffer, $\mathrm{pH}$ 8.1) and sonicated to disrupt the cells. Following centrifugation $\left(50,000 \times g, 1 \mathrm{~h}, 4^{\circ} \mathrm{C}\right)$ and filtration with a $22 \mu \mathrm{m}$ syringe filter unit, cell lysate containing untagged $\mathrm{Z}_{\mathrm{HER} 2: 2891} \mathrm{DCS}$ was subjected to ion exchange chromatography. The chromatographic separation was performed using an ÄKTA chromatography system (GE Healthcare, Chicago, IL, USA) with a weak cation exchanger column, HiTrap CM Fast Flow (GE Healthcare).

The elution of the affibody was performed by grading the salt concentration (from $10 \mathrm{mM}$ to $1 \mathrm{M} \mathrm{NaCl}$ ). Then the HEPES buffer $\mathrm{pH} 8.1$ was exchanged to the conjugation buffer ( $25 \mathrm{mM}$ phosphate, $150 \mathrm{mM} \mathrm{NaCl}, 0.5 \mathrm{mM}$ EDTA pH 6.8) using a HiTrap Desalting, $1 \times 5 \mathrm{~mL}$ column (GE Healthcare) prepacked with Sephadex G-25 Superfine. Aliquots of affibody were stored at $-80^{\circ} \mathrm{C}$.

\subsection{MMAE Conjugation Reaction and $Z_{H E R 2: 2891}$ DCS-MMAE Purification}

MMAE conjugation reaction was performed according to the method described by Sochaj-Gregorczyk et al. [21]. Briefly, for the conjugation reaction, a $30 \mathrm{mM}$ solution 
of non-reduced ZHER2:2891-DCS in $25 \mathrm{mM}$ sodium phosphate, $150 \mathrm{mM} \mathrm{NaCl}$, and $0.5 \mathrm{mM}$ EDTA pH 6.8 was incubated with $2.5 \mathrm{M}$ excess of MC-Val-Cit-PABC-MMAE (maleimidocaprylvaline-citruline-p-amino-benzyloxycarbonyl-monomethyl auristatin E) (ChiroBlock $\mathrm{Gmb}$ ) for $12 \mathrm{~h}$ at room temperature.

After the conjugation reaction, the mixture was purified by hydrophobic interaction chromatography high-performance liquid chromatography (HIC-HPLC) using an Agilent Eclipse XDB-C18 column and an Agilent 1200 HPLC Liquid Chromatography System (Santa Clara, CA, USA). To elute the affibody we used increasing concentrations of acetonitrile from $20 \%$ of buffer A ( $\mathrm{dH}_{2} \mathrm{O}, 0.1 \%$ TFA) to $50 \%$ buffer B (acetonitrile, $0.1 \%$ TFA). The peak containing $\mathrm{Z}_{\mathrm{HER2} 22891} \mathrm{DCS}-\mathrm{MMAE}$ conjugates was collected and lyophilized.

\subsection{Reagents}

Trastuzumab was purchased from Hoffman-La Roche Ltd. (Basel, Switzerland). MTT (3-(4,5-dimethylthiazol-2-yl)-2,5-diphenyltetrazolium bromide) and the Annexin V-FITC Apoptosis Detection kit were purchased from Sigma-Aldrich (Milan, Italy). McCoy's 5a medium, Dulbecco's Modified Eagle's Medium, Fetal Bovine Serum (FBS), L-glutamine, Penicillin, and streptomycin were purchased from Euroclone (Milan, Italy). iScript gDNA Clear cDNA Synthesis Kit, the iTaq Universal SYBR Green Supermix, and ECL Western Blotting Detection Reagent were purchased from Biorad (Milan, Italy). ErbB2 (HER2) monoclonal antibody (clone 3B5) was purchased from Thermo Fisher Scientific (Milan, Italy) and HRP-labeled goat anti-mouse IgG was purchased from Abcam (Milan, Italy).

\subsection{Cell Lines}

Human breast cancers SK-BR-3 (high HER-expressing cells) and MDA-MB-231 (basal HER-expressing cells) cell lines were purchased from ATCC. The ZR-75-1 cell line (which overexpresses HER2 [27] without gene amplification [28]) was a generous gift from Dr Elisa Caiola, Mario Negri Institute, Milan. SK-BR-3 cell line (ATCC HTB-30) was cultured in McCoy's 5a medium (Euroclone) supplemented with 10\% Fetal Bovine Serum (FBS). ZR-751 cells (ATCC CRL-1500) were cultivated in RPMI-1640 medium (Euroclone) supplemented with 10\% FBS. MDA-MB-231 cell line (ATCC HTB-26) was grown in Dulbecco's Modified Eagle's Medium (DMEM; Euroclone) supplemented with 10\% FBS.

Cells were cultured in $100 \mathrm{~mm}$ dishes at $37^{\circ} \mathrm{C}$ in a humidified atmosphere containing $5 \% \mathrm{CO}_{2}$, and when they reached confluence, cells were passaged using a Trypsin-EDTA solution.

\subsection{Cell Viability Assay}

Cells were seeded in 24 well-plates at a density of $1 \times 10^{5}$ cells $/$ well and $7 \times 10^{4}$ cells/well, respectively, and then left to grow for $24 \mathrm{~h}$ at $37^{\circ} \mathrm{C}$. At confluency, cells were treated with increasing concentrations of trastuzumab and $Z_{\text {HER2:2891 }}$ DCS-MMAE. $Z_{\text {HER2:2891 }}$ DCS not conjugated with MMAE was used as a negative control.

Cell viability upon treatments was evaluated by the MTT method. $\mathrm{IC}_{50}$ values were calculated using GraphPad Prism software (GraphPad Prism software, San Diego, CA, USA).

\subsection{Cell Proliferation Assay}

Cells were seeded in 24 -well plates at a density of $2 \times 10^{6}$ cells $/$ well. After $24 \mathrm{~h}$, media were removed, and cells were incubated for $72 \mathrm{~h}$ with medium containing $0.4 \%$ FBS to synchronize cells at $G_{0}$ phase of the cell cycle. After $72 \mathrm{~h}$, control dishes were counted with a Coulter Counter (Beckman Coulter, Life Scientific, Milan, Italy) and this was considered the "basal" number of cells at T0. Consequently, cells were treated with 5-100-500 nM and $1.25 \mu \mathrm{M}$ of trastuzumab and 5-100 and $500 \mathrm{nM}$ of $Z_{\text {HER2:2891 }}$ DCS-MMAE or $Z_{\text {HER2:2891 }}$ DCS not conjugated with MMAE in medium supplemented with 10\% of FBS for 24, 48, and $96 \mathrm{~h}$. Cells number were measured and compared to the zero time-point. 


\subsection{In Vitro Directional Migration (Wound Healing Assay)}

Cells were plated in 24-well plates and grown to confluence. Cell monolayers were scratched with a $200 \mu \mathrm{L}$ pipet tip in a straight line. Thereafter, the cell monolayer was washed with growth medium to remove detached cells. Cells were then incubated with medium containing $0.4 \%$ FBS and 5,100 , and $500 \mathrm{nM}$ of $Z_{\text {HER2:2891 }}$ DCS-MMAE or 5-100$500 \mathrm{nM}$ and $1.25 \mu \mathrm{M}$ of trastuzumab. Images of the wounded area were taken at the same spot at different time points $(0,6,24,48$, and $72 \mathrm{~h})$ using an inverted microscope (Axiovert 200; Carl Zeiss, $10 \times$ objective lens) equipped with a digital camera. Quantification of the wound area was performed using ImageJ, and cell migration was expressed as a percentage of wound areas at different time-points compared to initial wound area (T0).

\subsection{Apoptosis Analysis}

Cell apoptosis was performed using an Annexin V-FITC Apoptosis Detection kit (Sigma-Aldrich) according to the manufacturer instructions. Briefly, SK-BR-3 and MDAMB-231 were seeded in 24-well plates and grown to confluence. Cells were then treated for $10 \mathrm{~min}$ followed by drug removal and an additional $48 \mathrm{~h}$ of incubation in medium alone or for $48 \mathrm{~h}$ of continuous exposure to $\mathrm{Z}_{\mathrm{HER2} 22891}$ DCS-MMAE (5-500 $\mathrm{nM}$ ) and trastuzumab $(5 \mathrm{Nm}-1.25 \mu \mathrm{M})$. Next, cells were washed with PBS, resuspended in $300 \mu \mathrm{L}$ of binding buffer ( $25 \mathrm{mM} \mathrm{CaCl}_{2}, 1.4 \mathrm{M} \mathrm{NaCl}$, and $100 \mathrm{mM}$ HEPES/NaOH, pH 7.5), and incubated in the dark for 10 min with $5 \mu \mathrm{L}$ of Annexin V-FITC conjugate and $10 \mu \mathrm{L}$ of Propidium Iodide (PI). The percentage of apoptotic cells was evaluated with a flow cytometer (ACEA Biosciences NovoCyte, San Diego, CA, USA)

\subsection{1. $R N A$ Isolation and $q R T-P C R$}

SK-BR-3 and MDA-MB-231 were seeded in 24-well/plates at a density of $1 \times 10^{5}$ cells/well and $7 \times 10^{4}$ cells/well, respectively. After $24 \mathrm{~h}$, cells were treated with 5, 100, and $500 \mathrm{nM}$ of $Z_{\mathrm{HER} 2: 2891} \mathrm{DCS}-\mathrm{MMAE}$ and incubated for 24, 48, and $96 \mathrm{~h}$. At each time point, cells were washed once with PBS and RNA extraction was performed using a Direct-zol RNA MiniPrep Plus kit (Zymo Research, Milan, Italy). cDNA was generated by reverse transcription of RNA with an iScript gDNA Clear cDNA Synthesis Kit (Biorad). qRT-PCR was performed using iTaq Universal SYBR Green Supermix (Biorad). Samples were analyzed with a CFX CONNECT ${ }^{\mathrm{TM}}$ Real Time detection System (Biorad). Results were normalized to $\beta$ actin gene expression and the relative quantification was determined by the $2^{-\Delta \Delta C T}$ method. The primer sequences are listed in Table 2.

Table 2. List of real-time PCR primer sequences.

\begin{tabular}{ccc}
\hline Target Gene & Forward Primer & Reverse Primer \\
\hline ßactin & AGTGTGACGTGGACATCCGCA & GCCAGGGCAGTGATCTCCTTCT \\
HER2 & CCAGGACCTGCTGAACTGGT & GTACGAGCCGCACATCC \\
\hline
\end{tabular}

\subsection{Western Blot Analysis}

SK-BR-3 cells were treated with 5, 100, and $500 \mathrm{nM}$ of $\mathrm{Z}_{\mathrm{HER} 2: 2891} \mathrm{DCS}-\mathrm{MMAE}$ and incubated at $37^{\circ} \mathrm{C}$ for 24,48 , and $96 \mathrm{~h}$, while MDA-MB-231 cells were treated with 5, 100, and $500 \mathrm{nM}$ of $Z_{\text {HER2:2891 }}$ DCS-MMAE and incubated for $24 \mathrm{~h}$.

For the preparation of total cell lysates, cells were washed with ice-cold PBS and lysed with lysis buffer ( $\mathrm{NaCl} 150 \mathrm{mM}$, TRIS $50 \mathrm{mM} \mathrm{pH} \mathrm{7.6,} \mathrm{NONIDET} \mathrm{P-40} \mathrm{0.5 \%} \mathrm{and} \mathrm{protease}$ inhibitors (Merck, Milan, Italy)).

Protein concentration was determined using a Pierce BCA Protein Assay Kit (Pierce, Rockford, IL, USA) and samples were run on SDS-PAGE.

HER2 expression was evaluated by using a primary ErbB2 (HER2) monoclonal antibody (3B5) (Thermo Fisher Scientific) diluted 1:1000.

Densitometric analysis was performed using the ImageJ program. 


\subsection{Statistical Analysis}

Data are presented as the mean \pm SEM of 3 experiments performed in triplicates. Comparison between 2 groups was analyzed by independent $t$-test and the difference between 3 or more was determined by Dunnett post one-way ANOVA test. Results were considered statistically significant for $p$-values $<0.05$.

\section{Results}

\subsection{Expression and Purification of the $Z_{H E R 2: 2891-D C S}$}

In a previous study, since the affibody was fused with a GST tag, the anti-HER2 affi-

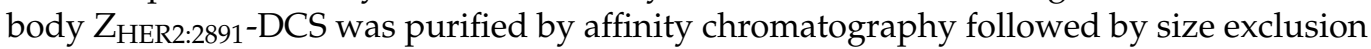
chromatography [21].

Since this method only allowed us to obtain a very low yield (1-5 mg of affibody from $1 \mathrm{~L}$ of bacteria culture), we developed a faster and more efficient method to purify the affibody, after GST tag removal.

In order to remove the sequence that encodes GST tag from the pDEST15- $Z_{\text {HER22891 }}$ DCS vector, an inverse PCR with 5'-phosphorylated primers was performed. The removal of the GST tag was confirmed by agarose gel electrophoresis. As shown in Figure 1, we observed a difference of size of the plasmid with GST (used as control) and without GST.

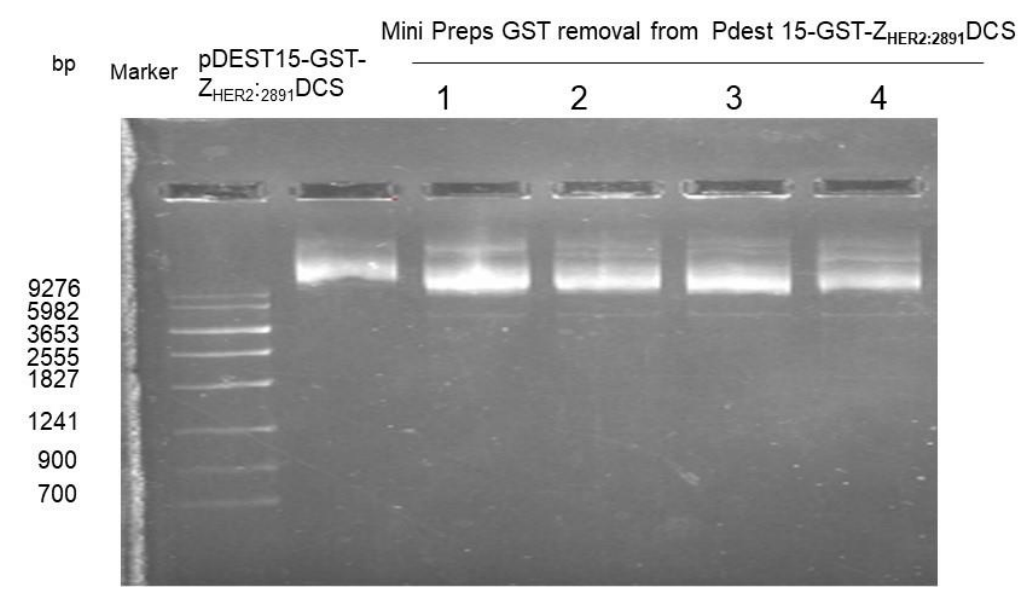

Figure 1. Isolation of DNA plasmid. An agarose gel electrophoresis was used to analyze the four reaction products (1-4) compared to the plasmid with GST.

For the purification of the untagged anti-HER2 affibody $Z_{\text {HER2:2891 }}$ DCS, we performed ion exchange chromatography. The 9.38 isoelectric point of our affibody was calculated by using the program EXPASY. We used HEPES buffer $\mathrm{pH}$ 8.1, because at this $\mathrm{pH}$, affibody is positively charged and therefore interacts with a cation-exchanger resin, such as the carboxymethyl cellulose, which is negatively charged (Figure 2).

All the fractions collected were analyzed by SDS-PAGE. As we can observe in Figure 3, each fraction contained untagged $Z_{\text {HER2:2891 }}$ DCS. Subsequently, the fractions were pooled together and subjected to desalting (Figure 3) to change the HEPES buffer of $\mathrm{pH} 8.1$ for a phosphate buffer of $\mathrm{pH}$ 6.8. We changed $\mathrm{pH}$ because the conjugation to MMAE via thiol-maleimide reaction occurs at a $\mathrm{pH}$ between 6.8-7.4. 


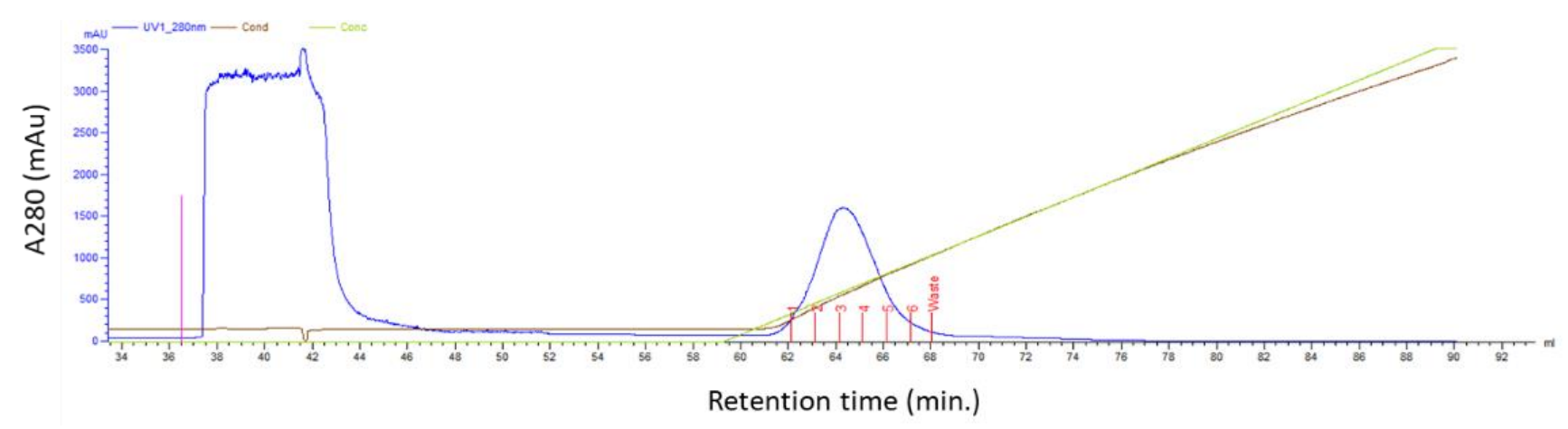

Figure 2. Ion exchange chromatography. The bacterial extract containing high levels of the untagged $\mathrm{Z}_{\mathrm{HER} 2: 2891}$ DCS was subjected to an ion exchange chromatography (CM sepharose Fast Flow $1 \mathrm{~mL}$ column) in HEPES buffer at $\mathrm{pH}$ 8.1. The affibody was eluted using a $\mathrm{NaCl}$ gradient (see material and methods).

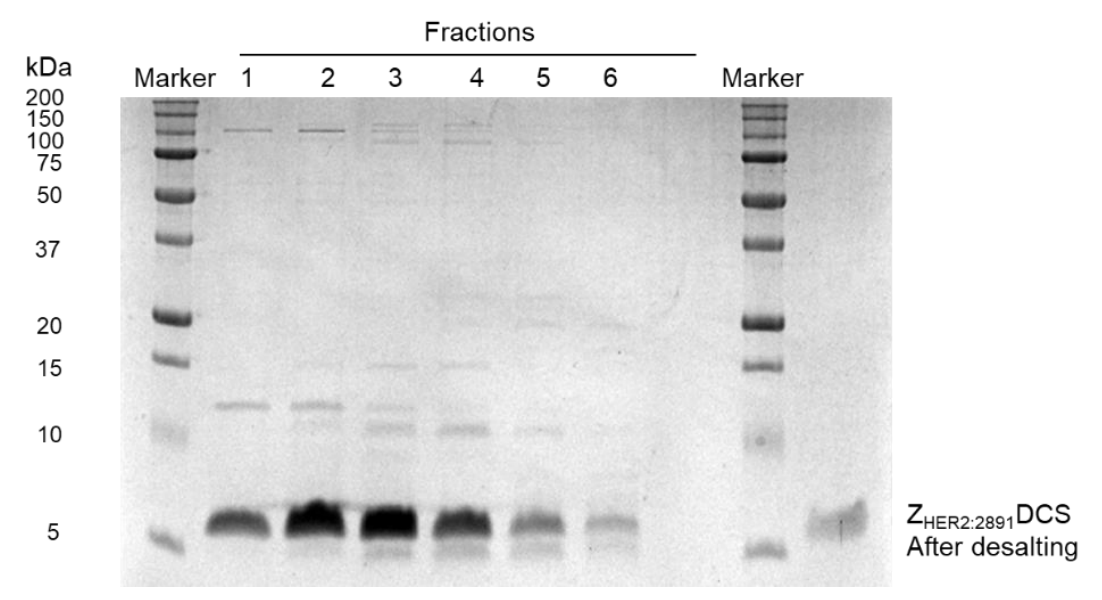

Figure 3. Fraction analysis on SDS-PAGE gel and desalting. All the fractions collected were analyzed on $15 \%$ SDS-PAGE gel. The fractions contained the untagged $Z_{\text {HER2:2891 were pooled together and }}$ subjected to desalting (HiTrap desalting column).

\subsection{Conjugation of MMAE to $Z_{H E R 2: 2891-D C S}$}

Affibody-MMAE conjugation was obtained according to the method described in Sochaj-Gregorczyk et al. [21]. After the conjugation reaction, the mixture was analyzed by HIC-HPLC. This chromatography allowed us to separate unconjugated proteins from the affibody conjugated to the hydrophobic auristatin E. The HPLC chromatogram described by Sochaj-Gregorczyk et al. confirmed the presence of a peak corresponding to $Z_{\mathrm{HER2} \text { :2891 }} \mathrm{DCS}$ conjugated with MMAE [21].

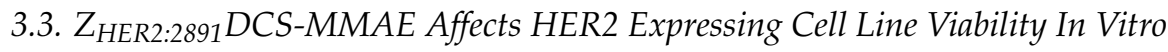

The cytotoxicity of $Z_{\mathrm{HER} 2: 2891}$ DCS-MMAE was evaluated in HER2-high expressor (SK-BR-3 and ZR-75-1) and low-expressor (MDA-MD-231) cell lines by MTT assay.

Cells were incubated with increasing concentrations (from $1 \mathrm{nM}$ to $500 \mathrm{nM}$ ) of $Z_{\text {HER2:2891 }}$ DCS-MMAE and $Z_{\text {HER2:2891 }}$ DCS not conjugated with MMAE, used as negative control, in two different ways: for $10 \mathrm{~min}$ followed by drug removal and an additional $48 \mathrm{~h}$ of incubation in medium alone, or 48 and $96 \mathrm{~h}$ of continuous exposure to the drugs.

As shown in Figure $4 \mathrm{~A}, 10$ min exposure with $\mathrm{Z}_{\mathrm{HER} 222891} \mathrm{DCS}-\mathrm{MMAE}$ was sufficient to reduce cell viability in a concentration-dependent and statistically significant manner in both HER2 expressing cell lines, with an $\mathrm{IC}_{50}$ value of $80.2 \mathrm{nM}$ in SK-BR-3 cells.

A stronger effect was observed after $48 \mathrm{~h}$ of continuous exposure to $Z_{\text {HER2:2891 }}$ DCSMMAE, with a $50 \%$ reduction of cell viability at a concentration of $5.33 \mathrm{nM}$ (Figure $4 \mathrm{~B}$ ), whereas the longest exposure time $(96 \mathrm{~h}$ ) reduced cell viability close to 0 at a concentration of $500 \mathrm{nM}$ with an $\mathrm{IC}_{50}$ of $7.13 \mathrm{nM}$ (Figure $4 \mathrm{C}$ ). $\mathrm{Z}_{\mathrm{HER} 2: 2891}$ DCS-MMAE also reduced ZR-75-1 
cell viability, although it was less effective (Figure 4A-C) and reached its IC50 of about $500 \mathrm{nM}$ after $48 \mathrm{~h}$ of incubation (Figure $4 \mathrm{C}$ ).

To evaluate if non-conjugated $Z_{\text {HER2:2891 }}$ DCS could affect SK-BR-3 and ZR-75-1cell viability, we treated the cells in the same experimental conditions. As shown in Figure 4A-C, affibody not conjugated to MMAE did not affect cell viability at all time points considered.

As expected, the $Z_{\text {HER2:2891 }}$ DCS-MMAE displayed only a weak in vitro cytotoxic effect on the MDA-MB-231 cells that express a basal level of HER2 at all time points, with a $15 \%$ reduction of cell viability only at the highest concentration used, and after $96 \mathrm{~h}$ of incubation (Figure 4A-C).

Since trastuzumab is used in patients with HER2-overexpressing metastatic breast cancer, we decided to use it as a reference compound. Therefore, we incubated both SK-BR-3 and ZR-75-1 cells with increasing concentrations of trastuzumab. As shown in Figure $4 \mathrm{~B}, \mathrm{C}$, at all time points and concentrations tested, trastuzumab showed a lower cytotoxic effect on these cell lines compared to $Z_{\text {HER2:2891 }}$ DCS-MMAE. Of note, not even at the additional higher concentration tested with trastuzumab $(1.25 \mu \mathrm{M})$ cell viability was reduced up to at least $50 \%$.

A

\section{$10 \mathrm{~min}$.}

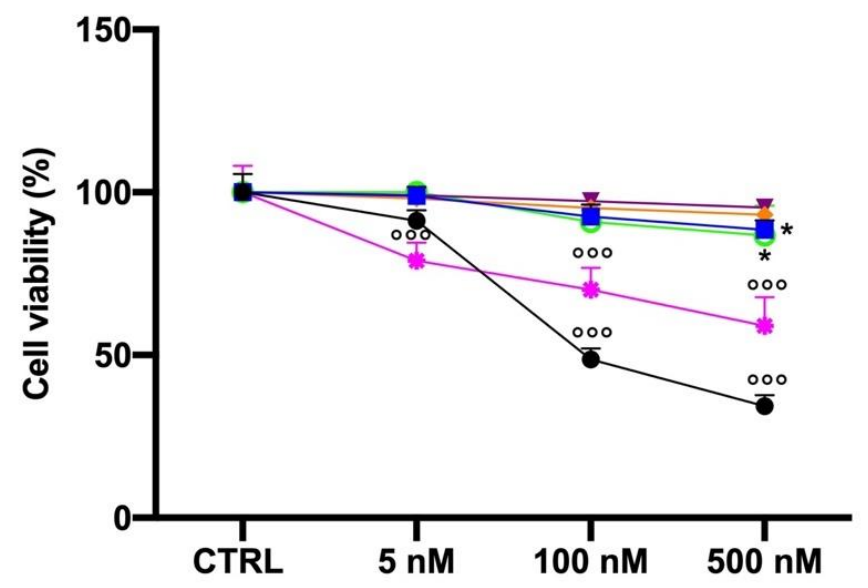

$\rightarrow Z_{\text {HER2:2891 DCS-MMAE SK-BR-3 }}$

- $\mathrm{Z}_{\text {HER2:2891 }}$ DCS not conjugated SK-BR-3

$\rightarrow Z_{\text {HER2:2891 DCS-MMAE MDA-MB-231 }}$

$\rightarrow \mathrm{Z}_{\text {HER2:2891 }} \mathrm{DCS}$ not conjugated MDA-MB-231

-* $\mathrm{Z}_{\text {HER2:2891 DCS-MMAE ZR-75-1 }}$

- $-Z_{\text {HER2:2891 }}$ DCS not conjugated ZR-75-1

\section{$48 \mathrm{~h}$}
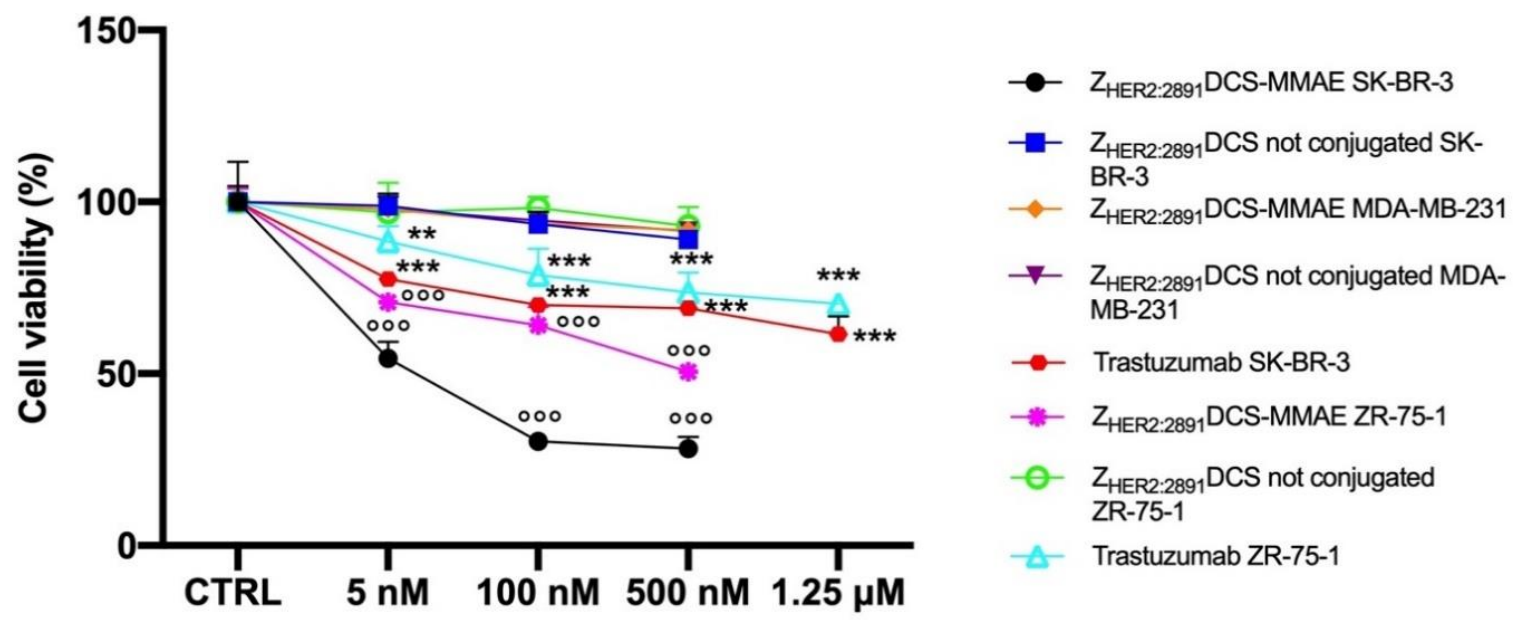

Figure 4. Cont. 
C

\section{$96 \mathrm{~h}$}
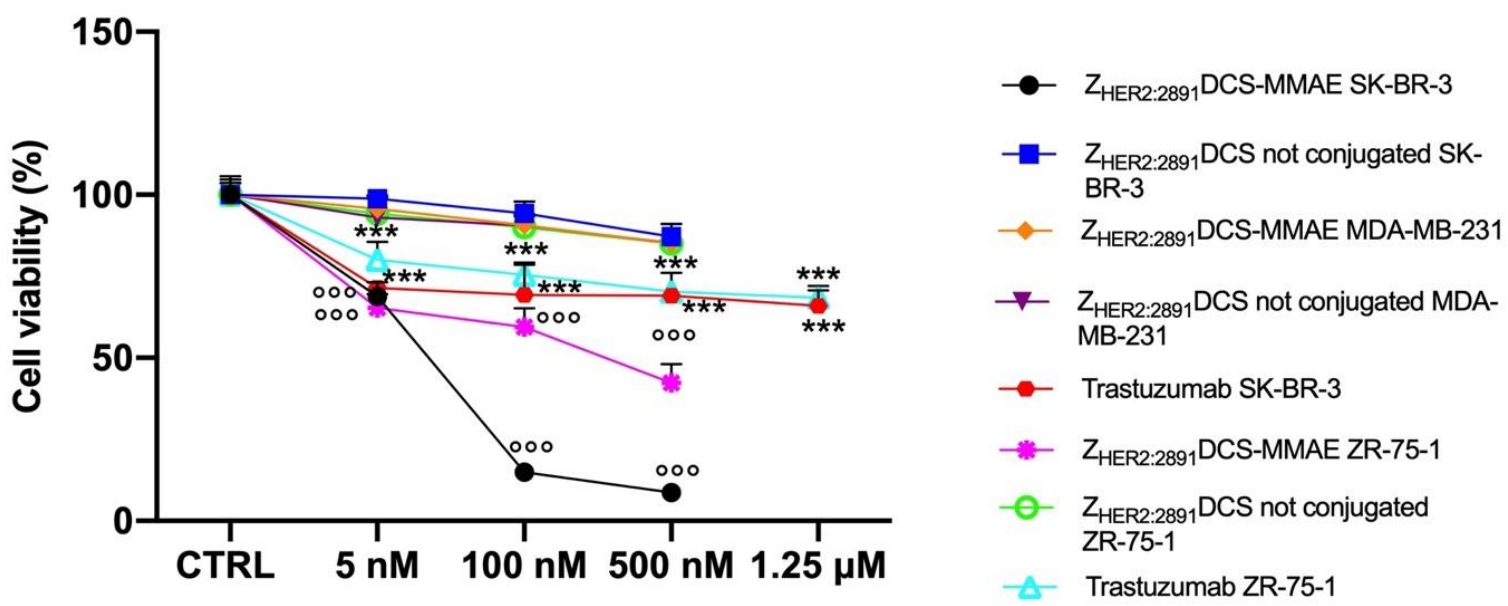

Figure 4. In vitro cell viability assay. SK-BR-3, ZR-75-1 and MDA-MB-231 cells were treated with increasing concentrations (from 5 to $500 \mathrm{nM}$ ) of $Z_{\text {HER2:2891 }}$ DCS-MMAE and not conjugated and with increasing concentrations of trastuzumab (from $5 \mathrm{nM}$ to $1.25 \mu \mathrm{M})$. The cytotoxicity was measured using an MTT assay after $10 \mathrm{~min}$ followed by drug removal and an additional $48 \mathrm{~h}$ of incubation in medium alone (Panel A) or for 48 and $96 \mathrm{~h}$ of continuous exposure to treatments (Panels B and $\mathbf{C}$, respectively). The $p$-value was determined by one-way ANOVA test with Dunnett post hoc test and considered significant for $p<0.05^{*}, p<0.01^{* *}, p<0.001^{* * *}$ compared to control and $p<0.001^{\circ 00}$ compared to $Z_{\text {HER2:2891 DCS not }}$ conjugated. Data are presented as mean \pm SEM.

\section{4. $Z_{H E R 2: 2891}$ DCS-MMAE Negatively Regulates HER2 Expressing Cell Line Proliferation}

Next, we investigated whether treatment with $Z_{\text {HER2:2891 }}$ DCS-MMAE would result in a decreased in vitro proliferation rate of HER2 overexpressing breast cancer cells.

As shown in Figure 5, $Z_{\text {HER2:2891 }}$ DCS-MMAE induced a concentration and timedependent inhibition of cell proliferation in SK-BR-3 and ZR-75-1 cell lines, already having a cytotoxic effect (indicated by a reduction in cell number below the starting basal cell number at time 0 (T0)) after $24 \mathrm{~h}$ of treatment, with the strongest effect observed after $48 \mathrm{~h}$. Interestingly, the $Z_{\text {HER2:2891 }}$ DCS-MMAE response was less evident after $96 \mathrm{~h}$ of treatment in both HER2 overexpressing cell lines (Figure 4, panels $C$ versus B).

As expected, in the same experimental conditions $Z_{\text {HER2:2891 }}$ DCS-MMAE displayed only a weak inhibition of cell proliferation in MDA-MB-231 at every time point and concentration tested (Figure 5, all panels).

As shown in Figure 5 (all panels), trastuzumab significantly inhibited cell in both SK-BR-3 and ZR-75-1 cell lines by more than $50 \%$ only at the highest concentration tested $(1.25 \mu \mathrm{M})$. 
A

\section{$24 \mathrm{~h}$}

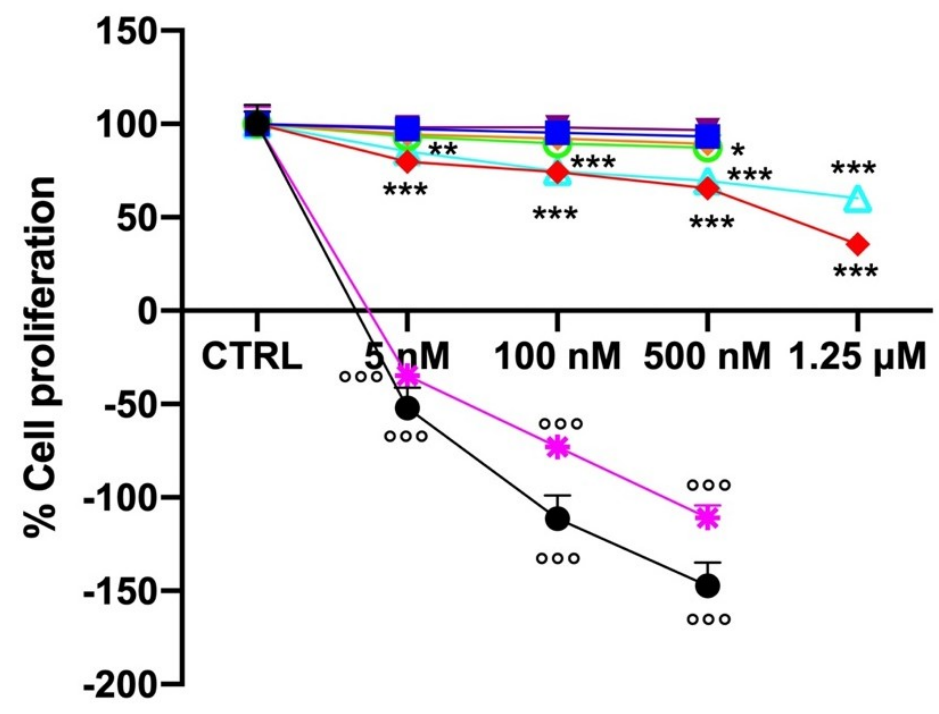

$48 h$

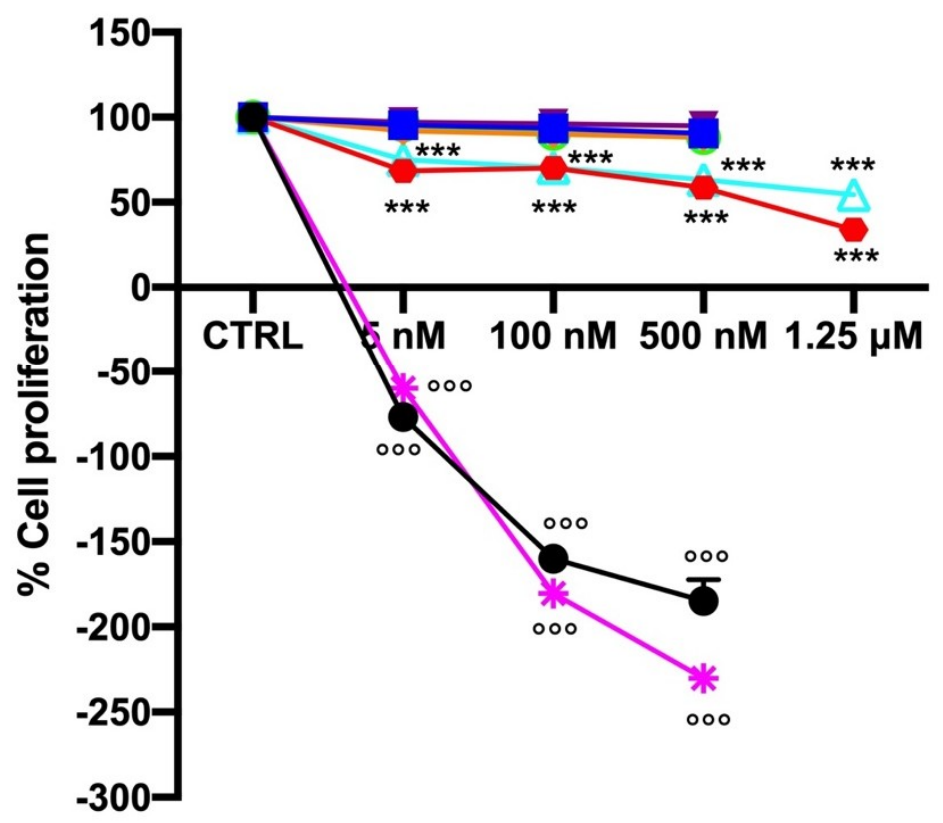

- $Z_{\text {HER2:2891 DCS-MMAE SK-BR-3 }}$

- $\mathrm{Z}_{\mathrm{HER} 2: 2891} \mathrm{DCS}$ not conjugated SK-BR-3

$\smile \quad Z_{\text {HER2:2891 }}$ DCS-MMAE MDA-MB-231

$\neg \mathrm{Z}_{\text {HER2:2891 }} \mathrm{DCS}$ not conjugated MDAMB-231

- Trastuzumab SK-BR-3

*- Z Z HER2:2891DCS-MMAE ZR-75-1

$\mathrm{Z}_{\text {HER2:2891 }}$ DCS not conjugated ZR-75-1

Trastuzumab ZR-75-1

Figure 5. Cont. 
C

\section{$96 \mathrm{~h}$}
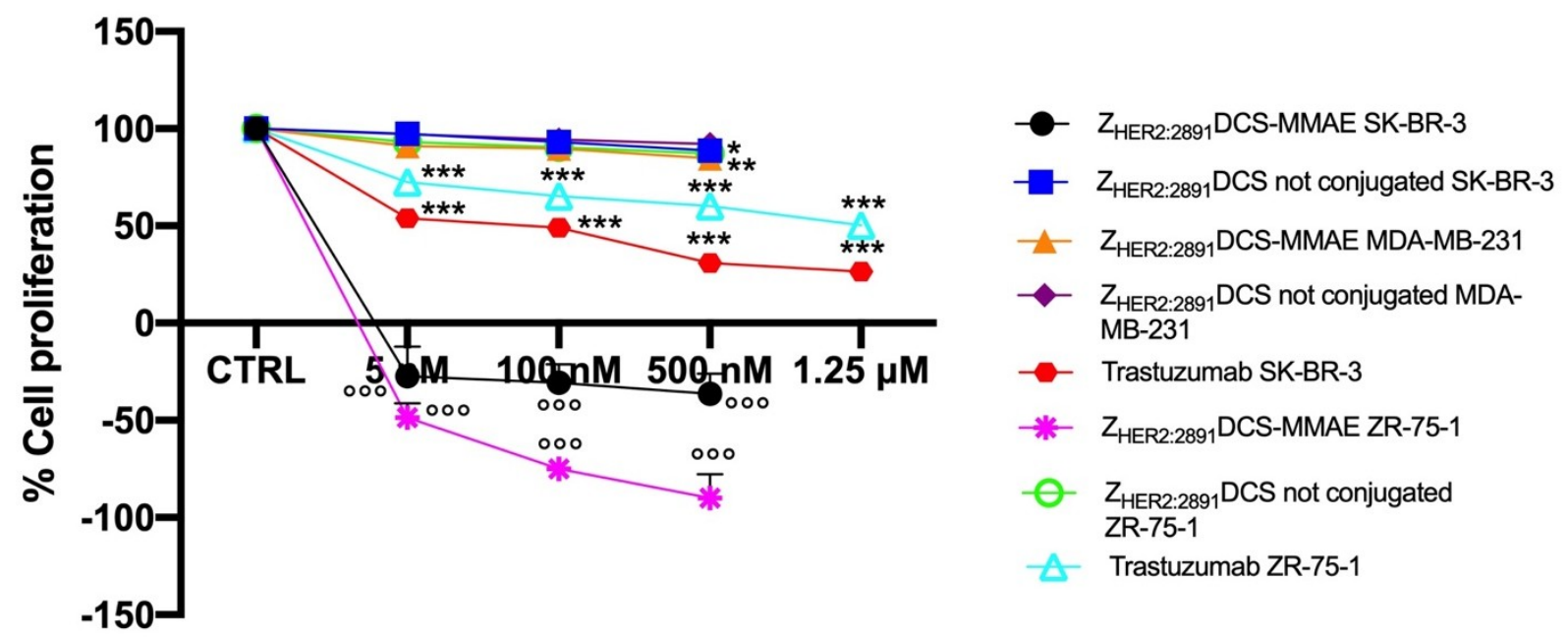

Figure 5. Cell proliferation assay. The effect on cell growth of trastuzumab and $Z_{\text {HER2:2891 }}$ DCS-MMAE and not conjugated, was tested in SK-BR-3, ZR-75-1 and MDA-MB-231 cells. Cells were treated with the substances for 24, 48, and 96 h (Panels A, B, and C, respectively). Cell number was measured with a Coulter Counter. The $p$-value was determined by one-way ANOVA test with Dunnett post hoc test and considered significant for $p<0.05^{*}, p<0.01^{* *} p<0.001^{* * *}$ compared to control and $p<0.001^{\circ 0 \circ}$ compared to $Z_{\mathrm{HER} 2: 2891} \mathrm{DCS}$ not conjugated. Data are presented as mean $\pm \mathrm{SEM}$.

\section{5. $Z_{H E R 2: 2891}$ DCS-MMAE Inhibits SK-BR-3 Migration}

Next, we evaluated whether $Z_{\text {HER2:2891 }}$ DCS-MMAE treatment would affect SK-BR-3 and MDA-MB-231 cell motility. A low percentage of serum (0.4\% of FBS) was used to minimize cell proliferation. The results of the wound healing experiments show that $\mathrm{Z}_{\text {HER2:2891 }}$ DCS-MMAE did not significantly affect the wound reclosure after $6 \mathrm{~h}$ (Figure $6 \mathrm{~A})$. On the contrary, after $24 \mathrm{~h}$ of treatment, $\mathrm{Z}_{\mathrm{HER} 2: 2891}$ DCS-MMAE significantly inhibited SK-BR-3 cell migration in a concentration-dependent manner compared with the untreated cells. After 48 and $72 \mathrm{~h}$ of incubation, cells were partially detached from the well surface, which made it impossible to measure the wounded area at these time-points (Data not shown).

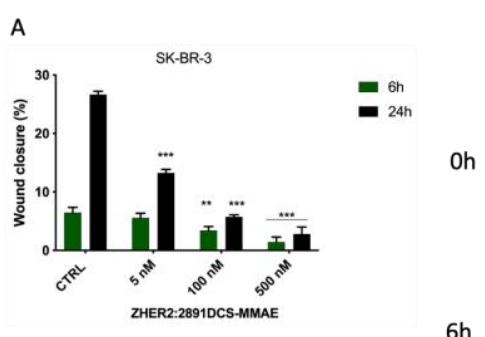

$6 h$
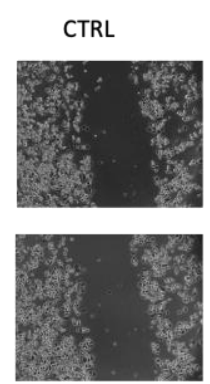

$24 \mathrm{~h}$

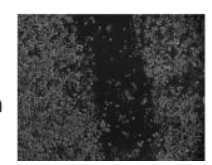

$5 \mathrm{nM}$
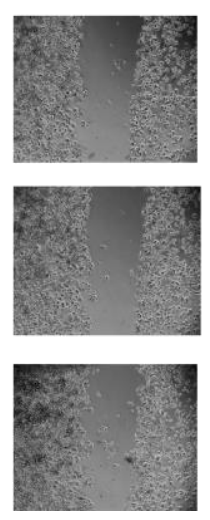

$100 \mathrm{nM}$
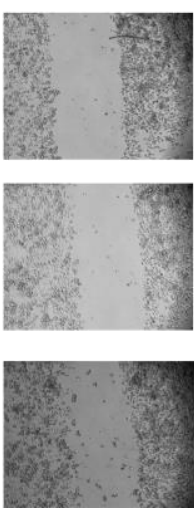

$500 \mathrm{nM}$
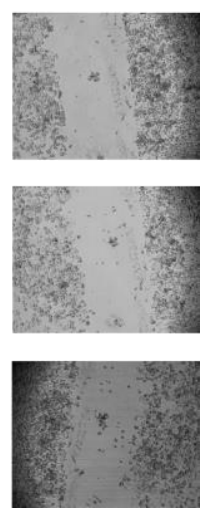

Figure 6. Cont. 


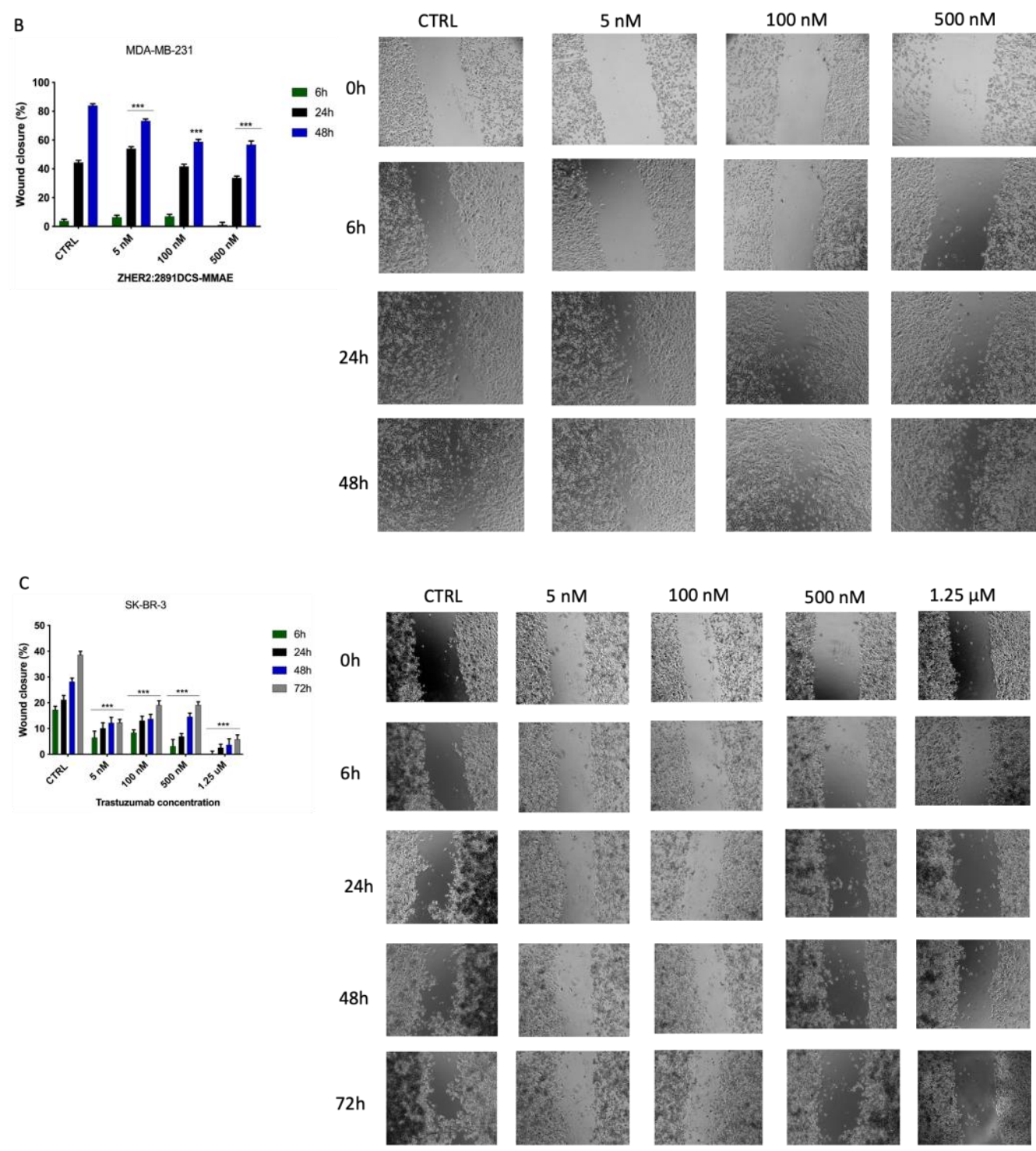

Figure 6. Cell migration assay. The effect on cell migration of $Z_{\text {HER2:2891 }}$ DCS-MMAE and trastuzumab, was tested in SK-BR-3 (A,C) and MDA-MB-231 cells (B) by wound healing assay. Cells were treated with the substances for 6, 24, 48, and $72 \mathrm{~h}$. The $p$-value was determined by one-way ANOVA test with Dunnett post hoc test and considered significant for $p<0.01^{* *}, p<0.001^{* * *}$ compared to control. Data are presented as mean $\pm \mathrm{SEM}$.

In MDA-MB-231 cells, both the untreated group and those treated with $\mathrm{Z}_{\mathrm{HER} 2: 2891} \mathrm{DCS}-$ MMAE showed a similar migration ability, which led to an almost complete reclosure of the wounded area after $48 \mathrm{~h}$ of cell incubation (Figure 6B).

As shown in Figure 6C, the migration rate of SK-BR-3 cells was significantly inhibited compared to the control by trastuzumab at all concentrations tested, ranging from $5 \mathrm{nM}$ to $1.25 \mu \mathrm{M}$.

\section{6. $Z_{H E R 2: 2891}$ DCS-MMAE Induces Apoptosis of SK-BR-3 Cells}

To further investigate the cytotoxic effects of $Z_{\text {HER2:2891 }}$ DCS-MMAE, we next assessed if the compound induced cell death in HER2 positive SK-BR-3 cells. Therefore, we analyzed by flow cytometry the expression of phosphatidylserine, a marker of apoptosis, together with DNA staining, as a readout of cell death due to membrane permeability, using annexin V-FITC and PI, respectively. Treatment with $Z_{\text {HER2:2891 }}$ DCS-MMAE increased the percentage of SK-BR-3 cells undergoing apoptosis (calculated by the sum of cells in early, positive to $\mathrm{AnV}$, and late, double positive for $\mathrm{AnV}$ and PI, apoptosis). 
After a 10 min exposure followed by drug removal and an additional $48 \mathrm{~h}$ of incu-

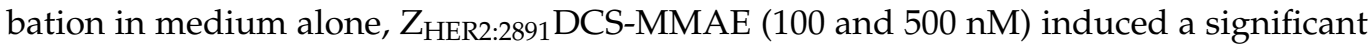
increase ( $40 \%$ each) of apoptotic cells compared to the control. After $48 \mathrm{~h}$ of treatment, even the lowest concentration of $5 \mathrm{nM}$ significantly increased the rate of apoptosis, by $40 \%$ (Figure $7 \mathrm{~A}$ ). In contrast, after $48 \mathrm{~h}$, no significant effect on apoptosis was observed following trastuzumab treatment in SK-BR-3 cells (Figure 7C).

A SK-BR-3
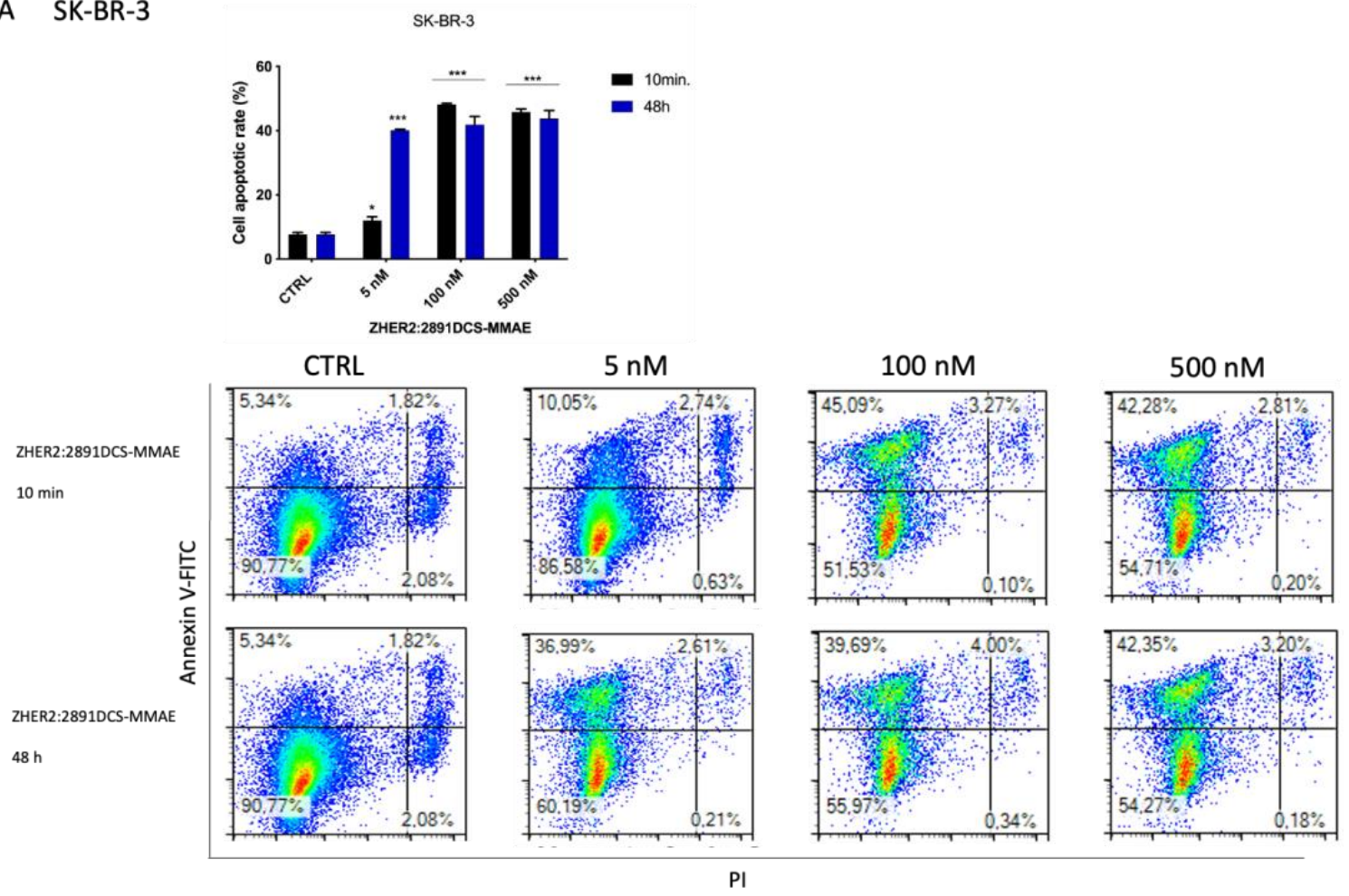

B MDA-MB-231
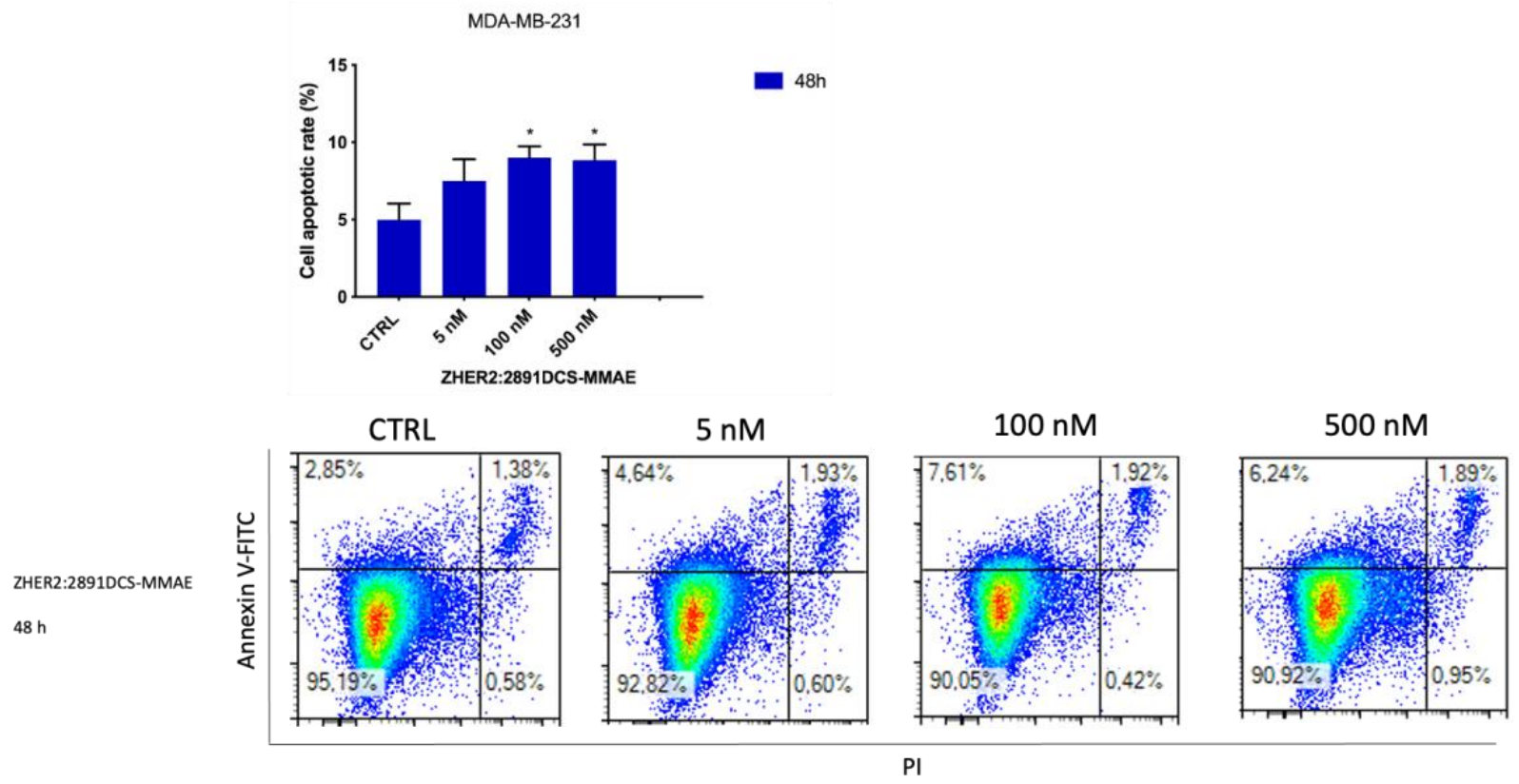

Figure 7. Cont. 
C SK-BR-3
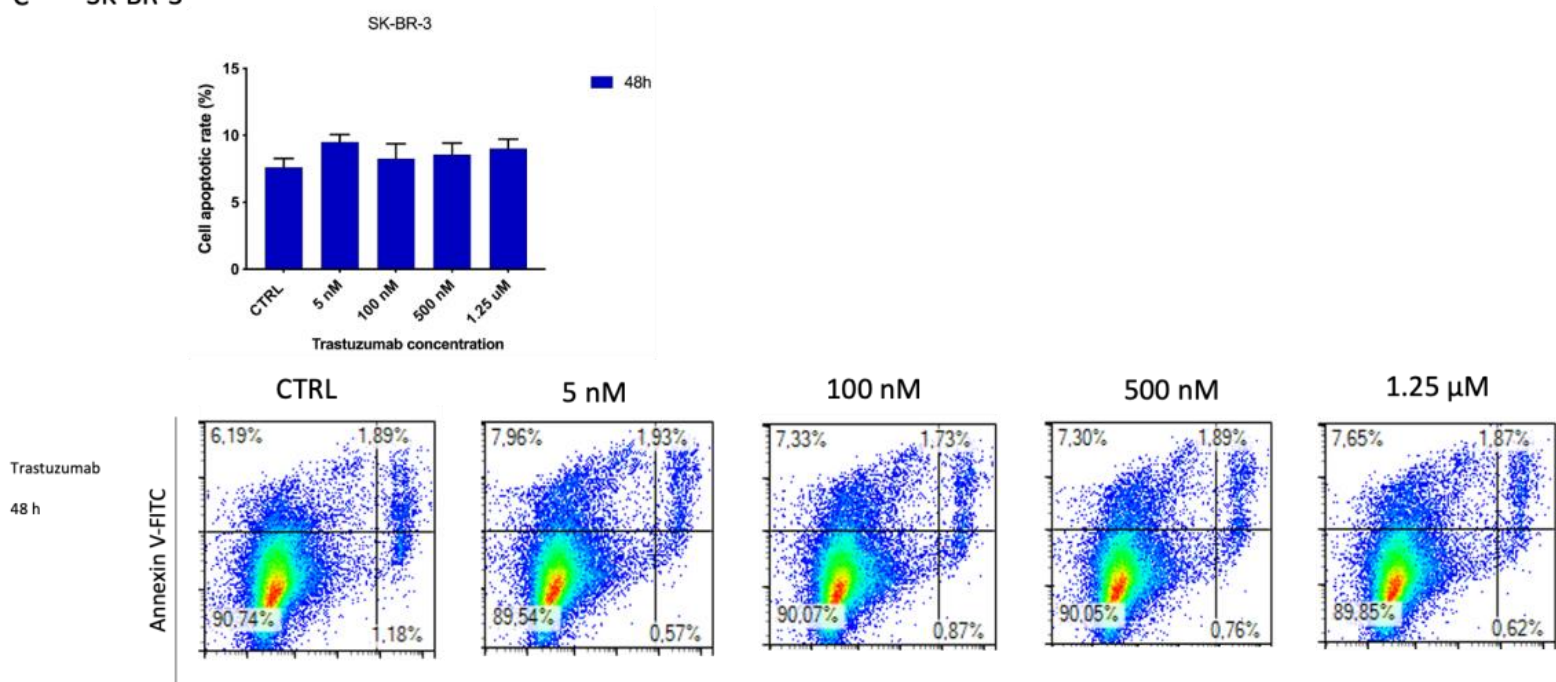

PI

Figure 7. Detection of cell death induced by $\mathrm{Z}_{\mathrm{HER} 2: 2891} \mathrm{DCS}-\mathrm{MMAE}$ and trastuzumab treatments. The effect of cellular death induced by $Z_{\text {HER2:2891 }}$ DCS-MMAE and trastuzumab was tested in SK-BR-3 (A,C) and MDA-MB-231 cells (B) by flow cytometry. The top left quadrant represents the percentage of early apoptotic cells (Annexin $\mathrm{V}^{+} / \mathrm{PI}^{-}$), the top right quadrant is the percentage of late apoptotic cells $\left(\right.$ Annexin $\mathrm{V}^{+} / \mathrm{PI}^{+}$); whereas the bottom left quadrant represents the percentage of

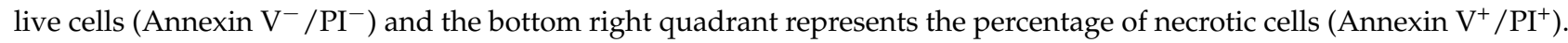
Cells were treated with the substances for $10 \mathrm{~min}$ followed by drug removal and an additional $48 \mathrm{~h}$ of incubation in medium alone (black bar) or for $48 \mathrm{~h}$ of continuous exposure to treatments (blue bar). The $p$-value was determined by one-way ANOVA test with Dunnett post hoc test and considered significant for $p<0.05^{*}, p<0.001^{* * *}$ compared to the control. Data are presented as mean \pm SEM.

As expected, $48 \mathrm{~h}$ of treatment with $\mathrm{Z}_{\mathrm{HER} 2: 2891} \mathrm{DCS}-\mathrm{MMAE}$ did not induce apoptosis in the MDA-MB-231 cell line compared to the control (Figure 7B). Moreover, as shown in the bottom right quadrant of each plot, treatment with $\mathrm{Z}_{\mathrm{HER2} 2891}$ DCS-MMAE or trastuzumab did not induce necrosis in either cell line.

\section{7. $Z_{H E R 2: 2891} D C S-M M A E$ Reduces HER2 Expression by SK-BR-3 Cells}

Subsequently, we tested the effects of $Z_{\mathrm{HER} 2: 2891}$ DCS-MMAE on the expression of HER2 in SK-BR-3 and MDA-MB-231 cells.

As shown in Figure 8, HER2 mRNA levels were significantly reduced $(p<0.001)$ by $Z_{\text {HER2:2891 }}$ DCS-MMAE in a concentration and time-dependent manner. The lowest concentration of $5 \mathrm{nM}$ significantly decreased HER2 transcript by $50 \%$ within $24 \mathrm{~h}$. The strongest effect was observed after $96 \mathrm{~h}$ of treatment, with an $80 \%$ inhibition of HER2 mRNA levels.
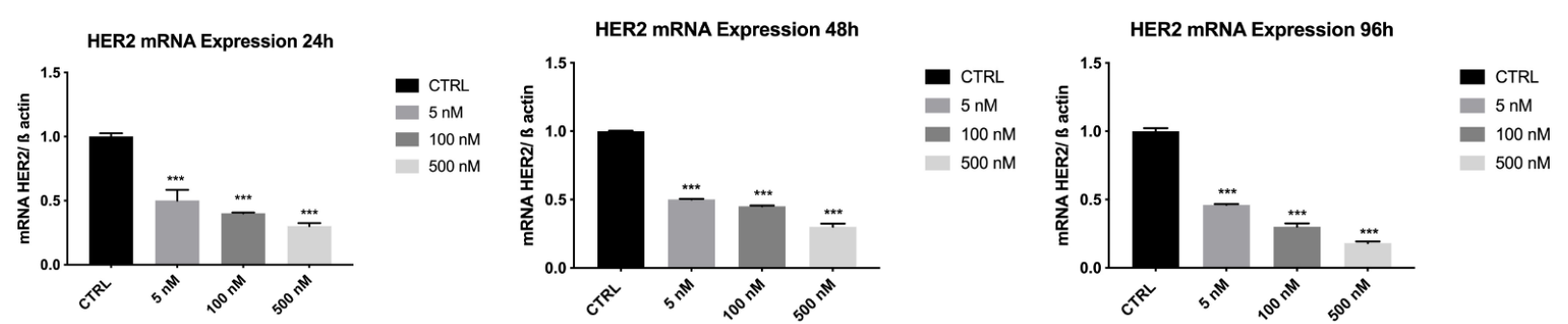

Figure 8. Effect of $\mathrm{Z}_{\mathrm{HER} 2: 2891}$ DCS-MMAE on HER2 expression in SK-BR-3 cells. Cells were treated for 24, 48, and $96 \mathrm{~h}$. The $p$-value was determined by one-way ANOVA test with Dunnett post hoc test and considered significant for $p<0.001 * * *$ compared to control. Data are presented as mean \pm SEM. 
Whereas, as shown in Figure 9, HER2 mRNA levels in MDA-MB-231 were not affected by $Z_{\text {HER2:2891 }}$ DCS-MMAE.

MDA-MB-231
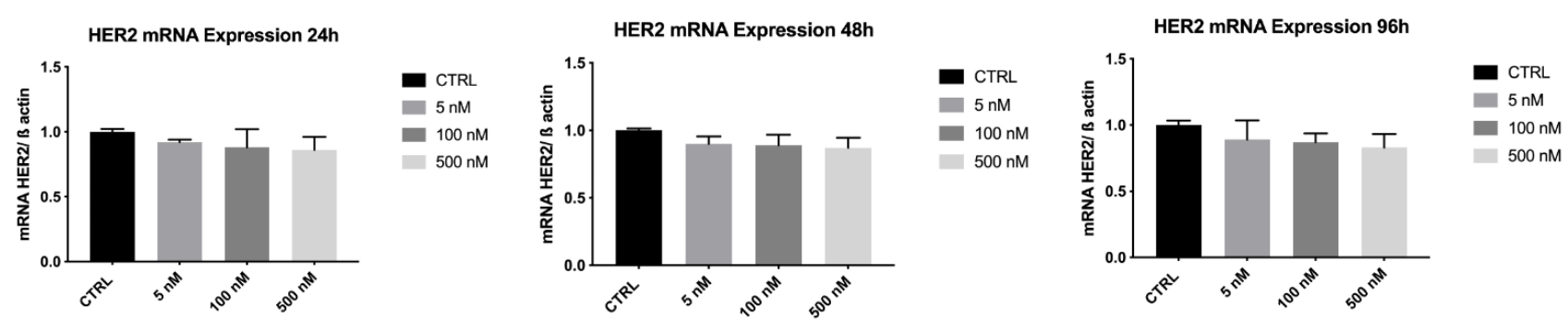

Figure 9. Effect of $\mathrm{Z}_{\mathrm{HER} 2: 2891}$ DCS-MMAE on HER2 expression in MDA-MB-231cells. Cells were treated for 24, 48, and $96 \mathrm{~h}$. The one-way ANOVA test did not reveal statistically significant differences between the control and treatments. Data are presented as mean \pm SEM.

To confirm the data obtained by RT-PCR, the expression of HER2 in SK-BR-3 cells, was evaluated by Western blot analysis. As shown in Figure 10, after $24 \mathrm{~h}$, the treatment with 5 and $100 \mathrm{nM}$ of $Z_{\text {HER2:2891 }}$ DCS-MMAE did not significantly affect HER2 expression. By contrast, $500 \mathrm{nM}$ of $Z_{\text {HER2:2891 }}$ DCS-MMAE significantly decreased HER2 expression by $90 \%$. The treatment with 100 and $500 \mathrm{nM}$ of $Z_{\text {HER2:2891 }}$ DCS-MMAE after $96 \mathrm{~h}$ was cytotoxic and we could not analyze HER2 protein expression.

As expected, MDA-MB-231 does not overexpress HER2.

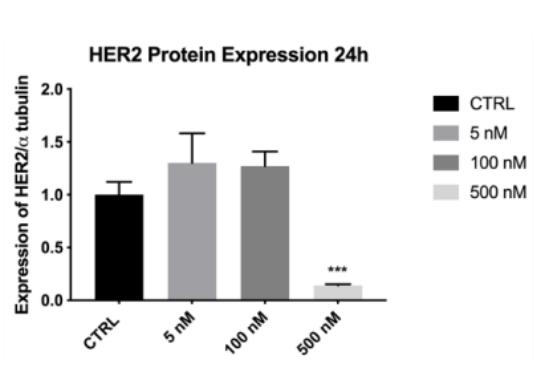

\section{SK-BR-3}
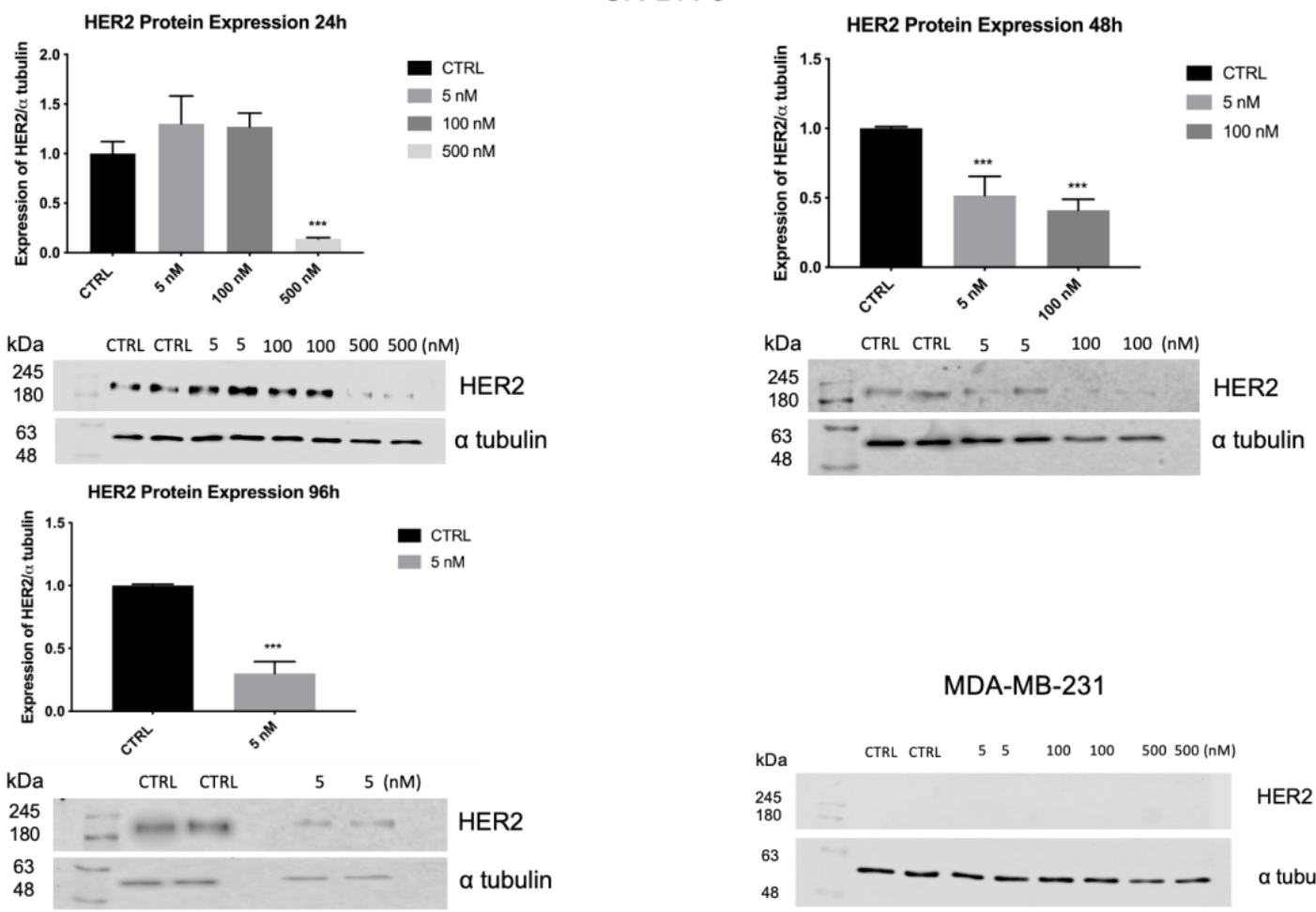

MDA-MB-231

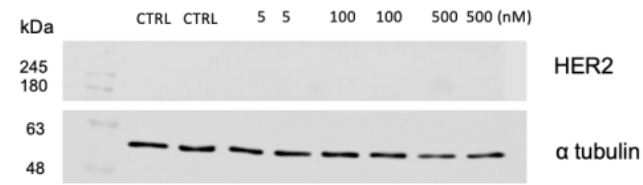

Figure 10. HER2 expression in SK-BR-3 and MDA-MB-231 cell lines. SK-BR-3 were treated for 24, 48, and 96 h, while MDA-MB-231 were treated for $24 \mathrm{~h}$. HER2 expression was measured by Western blot analysis and $\alpha$ tubulin was used as a loading control. The $p$-value was determined by one-way ANOVA test with Dunnett post hoc test and considered significant for $p<0.001^{* * *}$ compared to control. Data are presented as mean $\pm \mathrm{SEM}$. The complete western blots are shown in Supplementary Figures S1 and S2. 


\section{Discussion}

ADCs represent a successful class of anticancer agents that combine the selectivity of mAbs with the cytotoxic potency of a chemotherapeutic agent [29].

Tissue penetration and biodistribution are important factors, which most of the time seriously limit the response to treatment. One of the major limitations of these molecules is their large size $(150 \mathrm{kDa})$, which limits their ability to penetrate solid tumors [16]. In addition, due to their long serum half-life and slow blood clearance, they are not suitable for radioimmunotherapy or imaging purposes [16]. Another limitation is represented by the fact that many ADCs, including brentuximab vedotin and trastuzumab emtansine, still have a variable drug-to-antibody ratio and variable sites for drug conjugation, thus leading to the formation of heterogeneous species, each with different pharmacokinetic and efficacy profiles $[30,31]$. Therefore, a promising approach is represented by small carrier proteins able to interact specifically and with a high affinity (in the picomolar to the nanomolar range) with several targets overexpressed in tumor cells such as HER2, EGFR, and IGF-1R [32,33].

Affibody molecules are made of 58 amino acids (with a molecular weight of approximately $6.5 \mathrm{kDa}$ ) folded into a three-helical bundle and devoid of cysteines in their structure. Thus, they can be site-specifically modified by introducing one or more cysteine residues into the scaffold, permitting a site-specific conjugation of a cytotoxic payload. In the present work, a DCS that contains a single cysteine residue was introduced at the C-terminus of

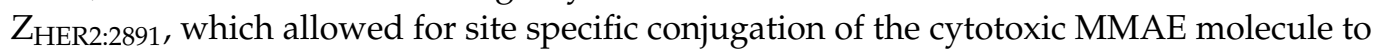
the affibody via thiol-maleimide chemistry.

Eigenbrot et al. demonstrated that these small molecules have remarkable biophysical properties, such as high thermal stability $\left(\mathrm{Tm}=67^{\circ} \mathrm{C}\right)$, rapid folding, and high solubility in aqueous solutions [34]. The favorable properties of the $Z_{\text {HER2 }}$ affibody molecule has led to their employment in diagnostic and therapeutic applications.

Affibodies represent a promising approach in terms of imaging because of their rapid biodistribution and rapid blood clearance, due to their small size. Affibodies against several cancer markers, such as HER2, have been developed for tumor imaging [17]. The first radiolabeling of affibody was investigated by Orlova et al. for imaging of HER2 expression. In this study, DOTA- $Z_{\text {HER2:342 }}$ (ABY-002) was efficiently labelled with indium111. A biodistribution study of 111 In-benzyl-DOTA- $Z_{\text {HER2:342 }}$ was performed in nude mice bearing LS174T xenografts. In vivo, 111In-benzyl-DOTA-Z $Z_{\text {HER2:342 }}$ demonstrated effective tumor uptake $4 \mathrm{~h}$ post injection [35].

For therapeutic applications, several groups have developed and characterized affibody molecules interacting with HER2 [36,37]. Zielinski et al. constructed a conjugate based on a modified version of the exotoxin A derived from Pseudomonas aeruginosa (PE38) fused to the $Z_{\text {HER2:342 }}$ and $Z_{\text {HER2:2891 }}$ affibodies. These constructs efficiently bind and kill cancer cells expressing HER2 after $1 \mathrm{~min}$ of exposure [36]. In addition, in vivo studies were carried out using xenograft HER2-overexpressing BT-474, SKOV3, and NCI-N87 tumors. HER2 affitoxin treatment resulted in a $60 \%$ volume reduction in BT-474 tumors after the first injection and a significant slowing down of tumor growth in mice bearing SKOV3 and NCI-N87 tumors [36]. Consistent with this, Gräslund et al. investigated the therapeutic efficacy of the $Z_{\text {HER2:2891 }}$ affibody conjugated with the cytotoxic maytansine derivate mcDM1 in a xenograft of HER2-overexpressing SKOV3 tumors. Treatment with $\mathrm{Z}_{\text {HER2:2891-ABD-E }}$-mcDM1 led to a significant reduction in tumor size, with a complete tumor regression in some animals at the end of the study [37]. These results demonstrate valuable evidence for the development of an anti-HER2 affibody in cancer-targeted therapy, which represents a promising alternative as a therapeutic agent in clinical practice and also in the veterinary field. In fact, similarly to human breast cancer, FMC is the third most common tumor type in cats. The feline homologue of HER2 is overexpressed in about $30-60 \%$ of FMC and is associated with aggressive behavior and poor prognosis [2]. A recently published paper by Ferreira et al. demonstrated that combined treatment with mAbs 
or an ADC targeting HER2 and the tyrosine kinase inhibitor lapatinib had a synergistic antiproliferative effect in feline cell lines [15].

The aim of our project was to develop a method for the efficient purification and characterization of the $Z_{\mathrm{HER} 2: 2891} \mathrm{DCS}$ affibody that specifically targets HER2. In contrast to the exotoxin and maytansine derivate used in previous studies, we used MMAE, a potent antimitotic agent that inhibits cell division by blocking the polymerization of tubulin.

In a previous study [21], the $Z_{\text {HER2:2891 }}$ DCS affibody was purified fused with a GST tag. However, this method turned out to be complicated and inefficient. In the present study, the GST tag was removed from the pDEST15-Z $Z_{\text {HER2:2891 }}$ DCS construct using an inverse PCR, which allowed us to express the affibody without any tag.

Subsequently, $Z_{\text {HER2:2891 }}$ DCS was subjected to an ion exchange chromatography that enabled us to obtain a one-step affibody purification compared to the previously published method, which was carried out in three steps (affinity chromatography, cleavage, gel filtration) [21]. The presently proposed purification method turned out to be simpler and faster, it did not require the removal of the tag, and it was 10 times more efficient than the previous one. The purity of our sample was estimated to be about $90 \%$, and we obtained a much higher yield ( $25 \mathrm{mg}$ from $1 \mathrm{~L}$ of culture).

To gain more insights into the pharmacological effect of $Z_{\text {HER2:2891 }}$ DCS-MMAE, we tested its in vitro effect on tumor cell growth, migration, and apoptosis pathways. As a reference molecule, the clinically approved monoclonal antibody, trastuzumab (Herceptin ${ }^{\circledR}$ ), was included in the study. $Z_{\mathrm{HER} 2: 2891} \mathrm{DCS}$ not conjugated with MMAE was used as a negative control.

To assess if $Z_{\text {HER2:2891 }}$ DCS-MMAE can selectively target HER2 overexpressing tumor cells, we used three different cell lines: the human adenocarcinoma cell line SK-BR-3 and ZR-75-1 that express high levels of HER2 (HER2+) $[15,27,28,38]$, and the human mammary gland adenocarcinoma MDA-MB-231, which expresses low (basal) levels of HER2 (HER2-) [39].

The MTT assay showed that $Z_{\text {HER2:2891 }}$ DCS-MMAE had a concentration-dependent and significant toxic effect in both the HER2 overexpressing cell lines, even at the lowest concentration tested of $5 \mathrm{nM}$ (Figure 4). On the contrary, $\mathrm{Z}_{\mathrm{HER} 2: 2891} \mathrm{DCS}$ not conjugated with MMAE did not affect cell viability. The fact that this toxic effect was due to a specific binding to the HER2 was demonstrated by the lack of any significant effects on cell viability in MDA-MB-231 (cells that have only a basal expression of HER2). Due to their small size, affibody molecules have a very short half-life $\left(\mathrm{T}_{1 / 2}<20 \mathrm{~min}\right)$, since they undergo a rapid renal excretion. As observed by Zielinski et al., the NCI-N87 gastric cell line exposed for 1 min to HER2-affitoxin, followed by an additional $72 \mathrm{~h}$ of incubation with medium, resulted in $90 \%$ cell death [36]. Our results on cell viability show that exposure to $Z_{\text {HER2:2891 }}$ DCSMMAE for $10 \mathrm{~min}$, followed by drug removal and an additional $48 \mathrm{~h}$ of incubation with medium alone, is sufficient to reduce both SK-BR-3 and ZR-75-1 cell viability by $60 \%$ and $40 \%$, respectively, at the highest concentration used.

The cytotoxic effect of $Z_{\text {HER2:2891 }}$ DCS-MMAE was confirmed by measuring cell death by flow cytometry. The total cells undergoing cell death by apoptosis was significantly increased (up to $40 \%$ ) in SK-BR-3 cells exposed for $10 \mathrm{~min}$ to $100 \mathrm{nM}$ of $\mathrm{Z}_{\mathrm{HER2} 22891}$ DCSMMAE. These findings support the evidence that the high affinity for HER2 receptor allows the affibody to selectively target the cytotoxic payload to HER2 positive cancer cells, thus exerting a cytotoxic activity.

As shown by the MTT assay and cell apoptosis analysis, our reference compound, trastuzumab, displayed only a low cytotoxic effect in SK-BR-3 and ZR-75-1 cells compared to $Z_{\text {HER2:2891 }}$ DCS-MMAE. Consistently, Abdollahpour-Alitappeh et al. showed that different concentrations of trastuzumab (from 1 to $1000 \mathrm{ng} / \mathrm{mL}$ ) exhibited only a weak cytotoxic effect in SK-BR-3 cells [40].

Since, HER2 overexpression is directly involved in the overstimulation of cell proliferation and migration, we evaluated the in vitro effects of $Z_{\text {HER2:2891 }}$ DCS-MMAE on these parameters. As shown in Figure 5, Z $Z_{\text {HER2:2891 }}$ DCS-MMAE in SK-BR-3 and ZR-75-1 cells 
induced cell death starting from $24 \mathrm{~h}$ of treatment, with the strongest effect observed after $48 \mathrm{~h}$. Interestingly, the antiproliferative effects of $Z_{\text {HER2:2891 }}$ DCS-MME were less evident after $96 \mathrm{~h}$ of treatment, which was probably due to the very short half-life of the affibody molecule. Alternatively, this data might be explained by a reduced cell surface expression of HER2 induced by the affibody, either by stimulating HER2 internalization or by reducing HER2 recycling once internalized.

We next utilized a wound healing assay to evaluate the impact of $Z_{\text {HER2:2891 }}$ DCSMMAE on cell migration. We found that $Z_{\text {HER2:2891 }}$ DCS-MMAE strongly inhibited SKBR-3 cell migration, as evidenced by a concentration-dependent decrease in wound area reclosure within $24 \mathrm{~h}$ of treatment. Images of the wounded area were also taken after 48 and $72 \mathrm{~h}$ (data not shown), but we were not able to measure the lesioned area because of the cell death induced by $Z_{\text {HER2:2891 }}$ DCS-MMAE and consequent cell detachment from the well surface.

In addition, SK-BR-3 treated with increasing concentrations of trastuzumab showed a significant concentration and time-dependent inhibition of cell growth and migration rate. Our results revealed that trastuzumab strongly inhibits cell proliferation, up to $70 \%$ at the highest concentration tested, and significantly suppresses SK-BR-3 migration rate compared with untreated cells. Consistently, Emlet et al. reported that trastuzumab, alone and in combination with erlotinib and bevacizumab, exerts a significant growth inhibition on HER2 overexpressing cell lines [41].

Subsequently, we evaluated whether treatment with $Z_{\text {HER2:2891 }}$ DCS-MMAE might affect HER2 expression. Our results demonstrated that, after $24 \mathrm{~h}$ of treatment, HER2 mRNA levels were significantly reduced (up to 50\%) in SK-BR-3 cells using the lowest concentration of $Z_{\text {HER2:2891 }}$ DCS-MMAE, compared to the control. Furthermore, as shown in Figure 10, $24 \mathrm{~h}$ of treatment with $500 \mathrm{nM}$ of $Z_{\text {HER2:2891 }}$ DCS-MMAE drastically decreased HER2 protein expression, by $90 \%$, while after 48 and $96 \mathrm{~h}$ the compound was cytotoxic and we could not see any protein on the gel. As expected, the presence of HER2 in MDA-MB-231 was too low to be detected. The fact that $Z_{\mathrm{HER} 2: 2891} \mathrm{DCS}-\mathrm{MMAE}$ can strongly downregulate HER2 expression suggests a potential use of HER2 affibody in the treatment of HER2 positive tumors.

\section{Conclusions}

In conclusion, our experimental data demonstrate that the cytotoxic conjugate formed by the anti HER2 affibody and monomethyl auristatin E efficiently interacts with HER2expressing cancer cells in vitro, allowing for a selective and specific delivery of the cytotoxic payload. This demonstrates that affibody may be used to target HER2 expressing cells. This technique might allow avoiding some of the problems encountered by using trastuzumab in clinics, such as poor tissue penetration due to its high molecular weight. In addition, the innovative purification procedure applied to isolate the affibody will permit much better yields and reduce production costs.

Supplementary Materials: The following are available online at https:/ /www.mdpi.com/article/ 10.3390/biology10080758/s1, Figure S1: representative western blots and densitometry analysis; Figure S2: HER2 expression in MDA-MB-231 cells. Representative western blot of ZHER2:2891DCSMMAE treatment (5, 100 and $500 \mathrm{nM})$ after $24 \mathrm{~h}$.

Author Contributions: Designed the experiments: I.D., A.S.-G.; Performed the experiments: I.D., S.C., A.S.-G., F.B.; Analyzed the data: I.D., S.C., A.S.-G., V.R.; writing—original draft preparation: I.D., S.B.; writing—review and editing: I.D., S.C., A.S.-G., I.C.; V.R.; supervision: J.O., A.C., S.B. All authors have read and agreed to the published version of the manuscript.

Funding: This research received no external funding.

Institutional Review Board Statement: Not applicable.

Informed Consent Statement: Not applicable.

Data Availability Statement: Data supporting reported results are available on request. 
Conflicts of Interest: The authors declare no conflict of interest.

\section{References}

1. Slamon, D.J.; Clark, G.M.; Wong, S.G.; Levin, W.J.; Ullrich, A.; McGuire, W.L. Human Breast Cancer: Correlation of Relapse and Survival with Amplification of the HER-2/neu Oncogene. Science 1987, 235, 177-182. [CrossRef]

2. Soares, M.; Ribeiro, R.; Najmudin, S.; Gameiro, A.; Rodrigues, R.V.; Cardoso, F.; Ferreira, F. Serum HER2 Levels are Increased in Cats with Mammary Carcinomas and Predict Tissue HER2 Status. Oncotarget 2016, 7, 17314-17326. [CrossRef]

3. Chen, J.-S.; Lan, K.; Hung, M.-C. Strategies to Target HER2/neu Overexpression for Cancer Therapy. Drug Resist. Updates 2003, 6, 129-136. [CrossRef]

4. Marmor, M.D.; Skaria, K.B.; Yarden, Y. Signal Transduction and Oncogenesis by ErbB/HER Receptors. Int. J. Radiat. Oncol. Biol. 2004, 58, 903-913. [CrossRef]

5. Okines, A.F.; Cunningham, D. Trastuzumab: A Novel Standard Option for Patients with HER-2-Positive Advanced Gastric or Gastro-Oesophageal Junction Cancer. Ther. Adv. Gastroenterol. 2012, 5, 301-318. [CrossRef]

6. Collins, D.M.; O’Donovan, N.; McGowan, P.; O'Sullivan, F.; Duffy, M.J.; Crown, J. Trastuzumab Induces Antibody-Dependent Cell-Mediated Cytotoxicity (ADCC) in HER-2-Non-Amplified Breast Cancer Cell Lines. Ann. Oncol. 2012, 23, $1788-1795$. [CrossRef]

7. Junttila, T.T.; Akita, R.W.; Parsons, K.; Fields, C.; Phillips, G.D.L.; Friedman, L.S.; Sampath, D.; Sliwkowski, M.X. LigandIndependent HER2/HER3/PI3K Complex Is Disrupted by Trastuzumab and Is Effectively Inhibited by the PI3K Inhibitor GDC-0941. Cancer Cell 2009, 15, 429-440. [CrossRef]

8. Molina, M.A.; Codony-Servat, J.; Albanell, J.; Rojo, F.; Arribas, J.; Baselga, J. Trastuzumab (herceptin), a Humanized Anti-Her2 Receptor Monoclonal Antibody, Inhibits Basal and Activated Her2 Ectodomain Cleavage in Breast Cancer Cells. Cancer Res. 2001, 61, 4744-4749. [PubMed]

9. Slamon, D.J.; Leyland-Jones, B.; Shak, S.; Fuchs, H.; Paton, V.; Bajamonde, A.; Fleming, T.; Eiermann, W.; Wolter, J.; Pegram, M.; et al. Use of Chemotherapy plus a Monoclonal Antibody against HER2 for Metastatic Breast Cancer that Overexpresses HER2. N. Engl. J. Med. 2001, 344, 783-792. [CrossRef]

10. Gajria, D.; Chandarlapaty, S. HER2-Amplified breast Cancer: Mechanisms of Trastuzumab Resistance and Novel Targeted Therapies. Expert Rev. Anticancer Ther. 2011, 11, 263-275. [CrossRef]

11. Panowski, S.; Bhakta, S.; Raab, H.; Polakis, P.; Junutula, J.R. Site-Specific Antibody Drug Conjugates for Cancer Therapy. $m A$ Abs 2014, 6, 34-45. [CrossRef] [PubMed]

12. Beck, A.; Reichert, J.M. Antibody-Drug Conjugates. $m A$ Abs 2013, 6, 15-17. [CrossRef] [PubMed]

13. Senter, P.D.; Sievers, E. The Discovery and Development of Brentuximab Vedotin for Use in Relapsed Hodgkin Lymphoma and Systemic Anaplastic Large Cell Lymphoma. Nat. Biotechnol. 2012, 30, 631-637. [CrossRef] [PubMed]

14. Phillips, G.D.L.; Li, G.; Dugger, D.L.; Crocker, L.M.; Parsons, K.L.; Mai, E.; Blättler, W.A.; Lambert, J.M.; Chari, R.V.; Lutz, R.J.; et al. Targeting HER2-Positive Breast Cancer with Trastuzumab-DM1, an Antibody-Cytotoxic Drug Conjugate. Cancer Res. 2008, 68, 9280-9290. [CrossRef]

15. Gameiro, A.; Nascimento, C.; Correia, J.; Ferreira, F. HER2-Targeted Immunotherapy and Combined Protocols Showed Promising Antiproliferative Effects in Feline Mammary Carcinoma Cell-Based Models. Cancers 2021, 13, 2007. [CrossRef]

16. Chames, P.; Van Regenmortel, M.; Weiss, E.; Baty, D. Therapeutic Antibodies: Successes, Limitations and Hopes for the Future. Br. J. Pharmacol. 2009, 157, 220-233. [CrossRef]

17. Löfblom, J.; Feldwisch, J.; Tolmachev, V.; Carlsson, J.; Ståhl, S.; Frejd, F.Y. Affibody molecules: Engineered Proteins for Therapeutic, Diagnostic and Biotechnological Applications. FEBS Lett. 2010, 584, 2670-2680. [CrossRef]

18. Nilsson, B.; Moks, T.; Jansson, B.; Abrahmsén, L.; Elmblad, A.; Holmgren, E.; Henrichson, C.; Jones, T.A.; Uhlen, M. A Synthetic IgG-Binding Domain Based on Staphylococcal Protein A. Protein Eng. Des. Sel. 1987, 1, 107-113. [CrossRef] [PubMed]

19. Wikman, M.; Steffen, A.-C.; Gunneriusson, E.; Tolmachev, V.; Adams, G.; Carlsson, J.; Stahl, S. Selection and characterization of HER2/neu-Binding Affibody Ligands. Protein Eng. Des. Sel. 2004, 17, 455-462. [CrossRef]

20. Nygren, P.A. Alternative Binding Proteins: Affibody Binding Proteins Developed from a Small Three-Helix Bundle Scaffold. FEBS J. 2008, 275, 2668-2676. [CrossRef]

21. Sochaj-Gregorczyk, A.M.; Serwotka-Suszczak, A.M.; Otlewski, J. A Novel Affibody-Auristatin E Conjugate With a Potent and Selective Activity against HER2+ Cell Lines. J. Immunother. 2016, 39, 223-232. [CrossRef]

22. Ma, D.; Hopf, C.E.; Malewicz, A.D.; Donovan, G.P.; Senter, P.D.; Goeckeler, W.F.; Maddon, P.J.; Olson, W.C. Potent Antitumor Activity of an Auristatin-Conjugated, Fully Human Monoclonal Antibody to Prostate-Specific Membrane Antigen. Clin. Cancer Res. 2006, 12, 2591-2596. [CrossRef] [PubMed]

23. Pettit, G.R.; Kamano, Y.; Herald, C.L.; Tuinman, A.A.; Boettner, F.E.; Kizu, H.; Schmidt, J.M.; Baczynskyj, L.; Tomer, K.B.; Bontems, R.J. The Isolation and Structure of a Remarkable Marine Animal Antineoplastic Constituent: Dolastatin 10. J. Am. Chem. Soc. 1987, 109, 6883-6885. [CrossRef]

24. Doronina, S.O.; Toki, B.E.; Torgov, M.Y.; Mendelsohn, B.A.; Cerveny, C.G.; Chace, D.F.; Deblanc, R.L.; Gearing, R.P.; Bovee, T.D.; Siegall, C.B.; et al. Development of Potent Monoclonal Antibody Auristatin Conjugates for Cancer Therapy. Nat. Biotechnol. 2003, 21,778-784, Erratum in 2003, 21, 941. 
25. Yip, V.; Lee, M.; Saad, O.; Ma, S.; Khojasteh, S.; Shen, B.-Q. Preclinical Characterization of the Distribution, Catabolism, and Elimination of a Polatuzumab Vedotin-Piiq (POLIVY®) Antibody-Drug Conjugate in Sprague Dawley Rats. J. Clin. Med. 2021, 10, 1323. [CrossRef]

26. Cancer, H.; Lines, C.; Abdollahpour-alitappeh, M.; Razavi-vakhshourpour, S.; Lotfinia, M.; Jahandideh, S. Monomethyl Auristatin E Exhibits Potent Cytotoxic Activity against Human Cancer Cell Lines SKBR3 and HEK293. Nov. Biomed. 2017, 5, 145-151. [CrossRef]

27. Yamaguchi, Y.; Hironaka, K.; Okawaki, M.; Okita, R.; Matsuura, K.; Ohshita, A.; Toge, T. HER2-Specific Cytotoxic Activity of Lymphokine-Activated Killer Cells in the Presence of Trastuzumab. Anticancer Res. 2005, 25, 827-832. [PubMed]

28. Magnifico, A.; Albano, L.; Campaner, S.; Delia, D.; Castiglioni, F.; Gasparini, P.; Sozzi, G.; Fontanella, E.; Menard, S.; Tagliabue, E. Tumor-Initiating Cells of HER2-Positive Carcinoma Cell Lines Express the Highest Oncoprotein Levels and Are Sensitive to Trastuzumab. Clin. Cancer Res. 2009, 15, 2010-2021. [CrossRef] [PubMed]

29. Abdollahpour-Alitappeh, M.; Lotfinia, M.; Gharibi, T.; Mardaneh, J.; Farhadihosseinabadi, B.; Larki, P.; Faghfourian, B.; Sepehr, K.S.; Abbaszadeh-Goudarzi, K.; Johari, B.; et al. Antibody-Drug Conjugates (ADCs) for Cancer Therapy: Strategies, Challenges, and Successes. J. Cell. Physiol. 2019, 234, 5628-5642. [CrossRef]

30. Junutula, J.R.; Raab, H.; Clark, S.; Bhakta, S.; Leipold, D.D.; Weir, S.; Chen, Y.; Simpson, M.; Tsai, S.P.; Dennis, M.S.; et al. Site-specific Conjugation of a Cytotoxic Drug to an Antibody Improves the Therapeutic Index. Nat. Biotechnol. 2008, 26, 925-932. [CrossRef]

31. Wagh, A.; Song, H.; Zeng, M.; Tao, L.; Das, T.K. Challenges and New Frontiers in Analytical Characterization of Antibody-Drug Conjugates. $m A$ bs 2018, 10, 222-243. [CrossRef]

32. Carlsson, J.; Nordberg, E.; Ekerljung, L.; Sahlberg, S.H.; Lennartsson, J.; Glimelius, B. Effects of an EGFR-Binding Affibody Molecule on Intracellular Signaling Pathways. Int. J. Oncol. 2010, 36, 967-972. [CrossRef] [PubMed]

33. Li, J.; Lundberg, E.; Vernet, E.; Larsson, B.; Höidén-Guthenberg, I.; Gräslund, T. Selection of Affibody Molecules to the Ligand Binding Site of the Insulin-Like Growth Factor-1 Receptor. Biotechnol. Appl. Biochem. 2010, 55, 99-109. [CrossRef]

34. Eigenbrot, C.; Ultsch, M.; Dubnovitsky, A.; Abrahmsén, L.; Härd, T. Structural Basis for High-Affinity HER2 Receptor Binding by an Engineered Protein. Proc. Natl. Acad. Sci. USA 2010, 107, 15039-15044. [CrossRef] [PubMed]

35. Orlova, A.; Tran, T.; Widström, C.; Engfeldt, T.; Karlström, A.E.; Tolmachev, V. Pre-Clinical Evaluation of [111In]-Benzyl-DOTAZHER2:342, a Potential Agent for Imaging of HER2 Expression in Malignant Tumors. Int. J. Mol. Med. 2007, 20, 397-404. [CrossRef] [PubMed]

36. Zielinski, R.; Lyakhov, I.; Hassan, M.; Kuban, M.; Shafer-Weaver, K.; Gandjbakhche, A.; Capala, J. HER2-Affitoxin: A Potent Therapeutic Agent for the Treatment of HER2-Overexpressing Tumors. Clin. Cancer Res. 2011, 17, 5071-5081. [CrossRef]

37. Xu, T.; Ding, H.; Vorobyeva, A.; Oroujeni, M.; Orlova, A.; Tolmachev, V.; Gräslund, T. Drug Conjugates Based on a Monovalent Affibody Targeting Vector Can Efficiently Eradicate HER2 Positive Human Tumors in an Experimental Mouse Model. Cancers 2020, 13, 85. [CrossRef]

38. Lin, T.-Y.; Wang, P.-W.; Huang, C.-H.; Yang, P.-M.; Pan, T.-L. Characterizing the Relapse Potential in Different Luminal Subtypes of Breast Cancers with Functional Proteomics. Int. J. Mol. Sci. 2020, 21, 6077. [CrossRef]

39. Subik, K.; Lee, J.-F.; Baxter, L.; Strzepek, T.; Costello, D.; Crowley, P.; Xing, L.; Hung, M.-C.; Bonfiglio, T.; Hicks, D.G.; et al. The Expression Patterns of ER, PR, HER2, CK5/6, EGFR, Ki-67 and AR by Immunohistochemical Analysis in Breast Cancer Cell Lines. Breast Cancer Basic Clin. Res. 2010, 4, 35-41. [CrossRef]

40. Abdollahpour-Alitappeh, M.; Lotfinia, M.; Bagheri, N.; Sepehr, K.S.; Habibi-Anbouhi, M.; Kobarfard, F.; Balalaie, S.; Foroumadi, A.; Abbaszadeh-Goudarzi, K.; Abolhassani, M. Trastuzumab-Monomethyl Auristatin E Conjugate Exhibits Potent Cytotoxic Activity In Vitro against HER2-Positive Human Breast Cancer. J. Cell. Physiol. 2019, 234, 2693-2704. [CrossRef] [PubMed]

41. Emlet, D.R.; Brown, K.A.; Kociban, D.L.; Pollice, A.A.; Smith, C.A.; Ong, B.B.L.; Shackney, S.E. Response to Trastuzumab, Erlotinib, and Bevacizumab, Alone and in Combination, is Correlated with the Level of Human Epidermal Growth Factor Receptor-2 Expression in Human Breast Cancer Cell Lines. Mol. Cancer Ther. 2007, 6, 2664-2674. [CrossRef] [PubMed] 